Portland State University

PDXScholar

$12-2-2016$

\title{
Unmanned Aerial Vehicle Based Structure from Motion Biomass Inventory Estimates
}

\author{
Emily Jane Bedell \\ Portland State University
}

Follow this and additional works at: https://pdxscholar.library.pdx.edu/open_access_etds

Part of the Environmental Studies Commons, Geographic Information Sciences Commons, and the Remote Sensing Commons

Let us know how access to this document benefits you.

\section{Recommended Citation}

Bedell, Emily Jane, "Unmanned Aerial Vehicle Based Structure from Motion Biomass Inventory Estimates" (2016). Dissertations and Theses. Paper 3368.

https://doi.org/10.15760/etd.5259

This Thesis is brought to you for free and open access. It has been accepted for inclusion in Dissertations and Theses by an authorized administrator of PDXScholar. Please contact us if we can make this document more accessible: pdxscholar@pdx.edu. 
Unmanned Aerial Vehicle Based Structure from Motion Biomass Inventory Estimates

$$
\text { by }
$$

Emily Jane Bedell

A thesis submitted in partial fulfillment of the requirements for the degree of

\author{
Master of Science \\ in \\ Mechanical Engineering
}

\begin{abstract}
Thesis Committee:
Evan Thomas, Chair

Gerald Recktenwald

Raúl Bayoán Cal

Michael Wing
\end{abstract}

Portland State University

2016 


\section{Abstract}

Riparian vegetation restoration efforts demand cost effective, accurate, and replicable impact assessments. In this thesis a method is presented using an Unmanned Aerial Vehicle (UAV) equipped with a GoPro digital camera to collect photogrammetric data of a 2.02-acre riparian restoration. A three-dimensional point cloud was created from the photos using Structure from Motion (SfM) techniques. The point cloud was analyzed and compared to traditional, ground-based monitoring techniques. Ground truth data collected using the status-quo approach was collected on $6.3 \%$ of the study site and averaged across the entire site to report stem heights in stems/acre in three height classes, 0-3 feet, 3-7 feet, and greater than 7 feet. The project site was divided into four analysis sections, one for derivation of parameters used in the UAV data analysis, and the remaining three sections reserved for method validation. The most conservative of several methods tested comparing the ground truth data to the UAV generated data produced an overall error of $21.6 \%$ and indicated an $\mathrm{r}^{2}$ value of 0.98 . A Bland Altman analysis indicated a $99 \%$ probability that the UAV stems/plot result will be within 159 stems/plot of the ground truth data. The ground truth data is reported with an $80 \%$ confidence interval of $+/-844$ stems/plot, thus the UAV was able to estimate stems well within this confidence interval. Further research is required to validate this method longitudinally at this same site and across varying ecologies. These results suggest that UAV derived environmental impact assessments at riparian restoration sites may offer competitive performance and value. 


\section{Acknowledgements}

Funding for this research was provided by the Vauther Family Foundation, the Portland State Institute for Sustainable Solutions, the Portland State SweetLab. In-kind support was provided by The Freshwater Trust.

The author wishes to express gratitude for the help and support of the following people: Evan Thomas (Portland State), Katie Fankhauser (Oregon Health and Science University), Michael Wing (Oregon State University), Jon Burnett (Oregon State University), Monique Leslie (The Freshwater Trust), Olivia Duren (The Freshwater Trust), Rob Bolduc, Vanessa Roberson-Rojas, Forest Bailey, and Jon Ray. 


\section{Table of Contents}

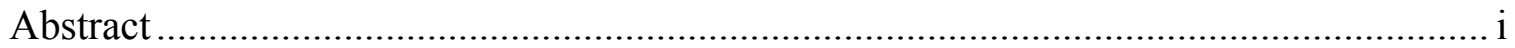

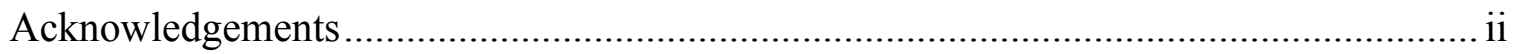

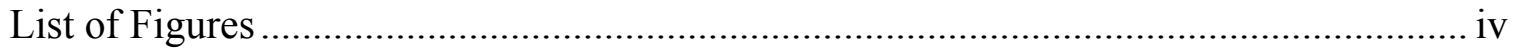

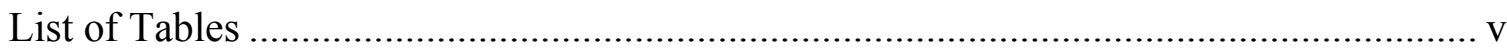

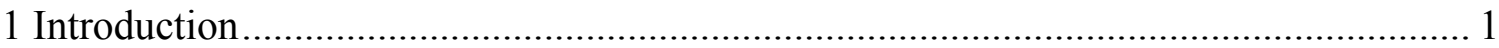

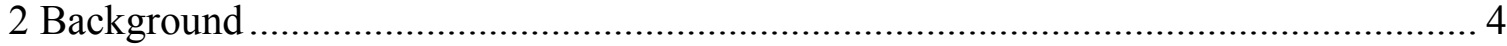

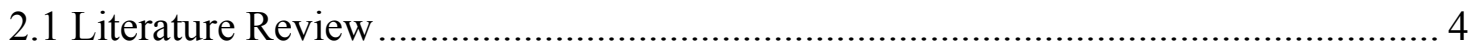

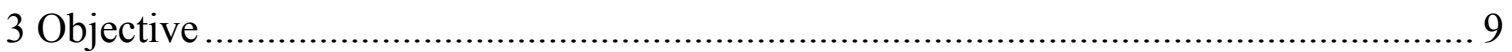

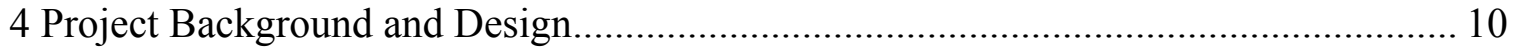

4.1 The Freshwater Trust Monitoring Procedures and Techniques ............................ 12

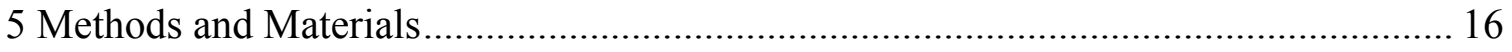

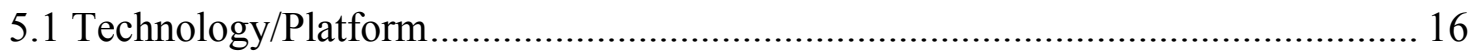

5.2 Flight and Photo Processing Procedure ............................................................... 17

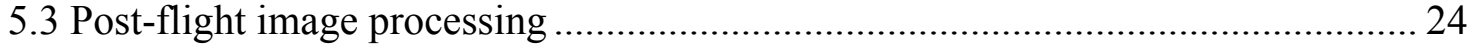

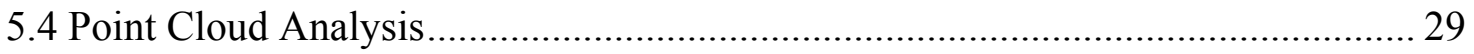

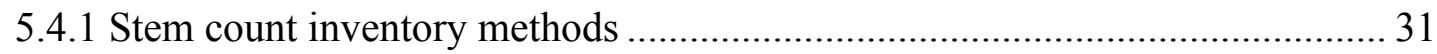

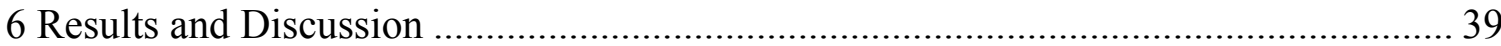

6.1 Proportional Allocation Method: Overall Field Data Results Comparison ............ 39

6.2 Transects Averaged Method: Localized Field Data Results Comparison............... 43

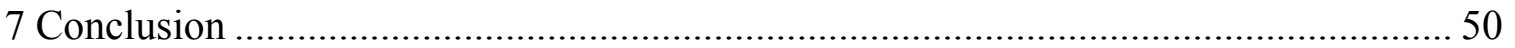

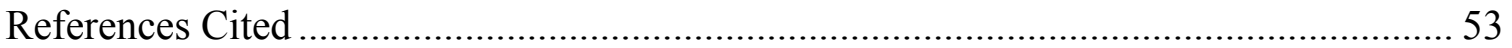




\section{List of Figures}

Figure 1: Cedar Creek Planting Area [21] ............................................................... 11

Figure 2: Performance standards for water quality trading riparian vegetation projects

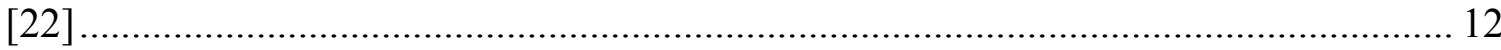

Figure 3: Revegetation monitoring transect layout [22] ............................................ 13

Figure 4: Hydrological zone boundaries in a riparian area [22] ................................. 14

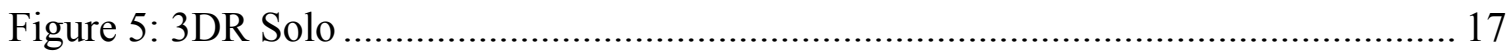

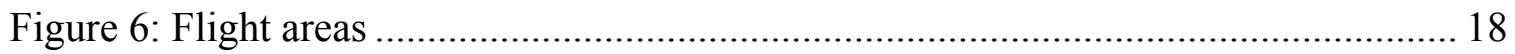

Figure 7: Flight area 1 a) Polygon drawn around area of interest b) Flight path flown perpendicular to area of interest, flight angle $=176^{\circ} \mathrm{c}$ ) Flight path flown parallel to the

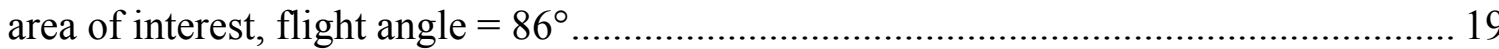

Figure 8: Flight area 2 a) Polygon drawn around area of interest b) Flight path flown perpendicular to area of interest, flight angle $=220^{\circ} \mathrm{c}$ ) Flight path flown parallel to area

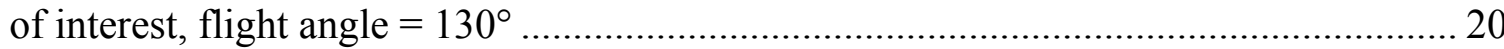

Figure 9: GCP with Trimble GeoExplorer 6000 Series GNSS receiver.......................... 21

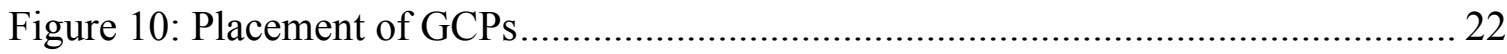

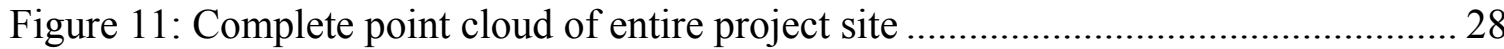

Figure 12: Detail of dense point cloud ....................................................................... 28

Figure 13: Analysis sections used for calibration and verification................................. 29

Figure 14: Point cloud visualization in FUSION ................................................... 30

Figure 15: Individual tree measurement in FUSION .................................................... 31

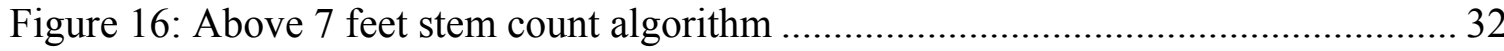

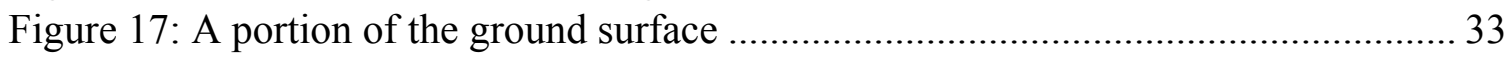

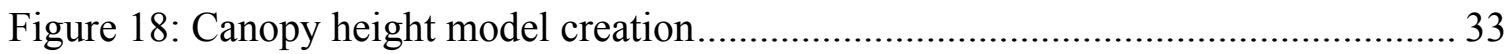

Figure 19: Below 7 feet stem count algorithm............................................................. 35

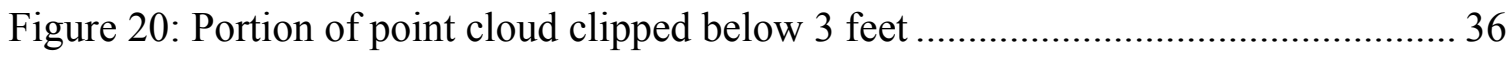

Figure 21: CHM of 0 to 3 feet height class................................................................ 37

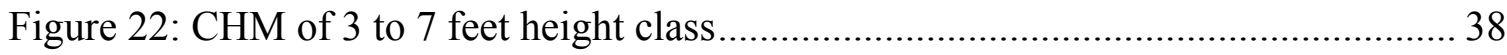

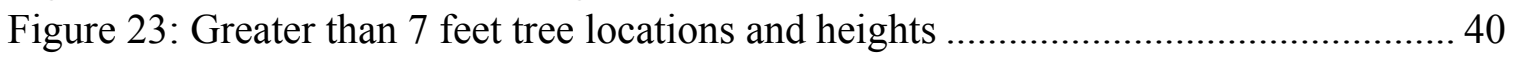

Figure 24: Linear regression of TFT vs. Drone results for the Proportional Allocation

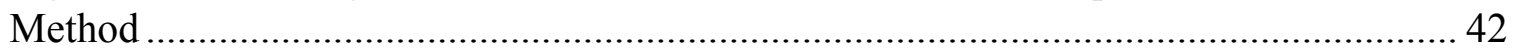

Figure 25: Bland Altman analysis of TFT vs. Drone results for the Proportional

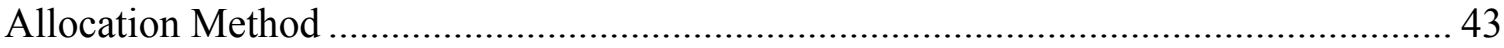

Figure 26: Linear regression of TFT vs. Drone results for Method 2 ............................ 46

Figure 27: Bland Altman analysis of TFT vs. Drone results for Method 2 .................... 47 


\section{List of Tables}

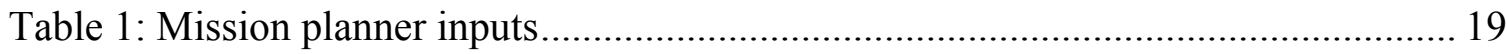

Table 2: GoPro Settings .......................................................................................... 23

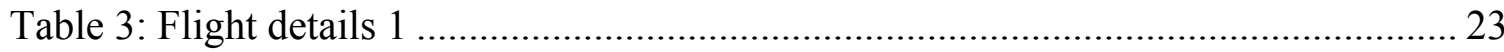

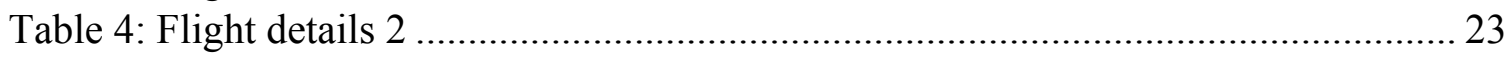

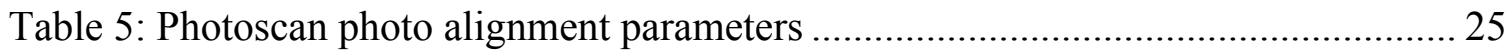

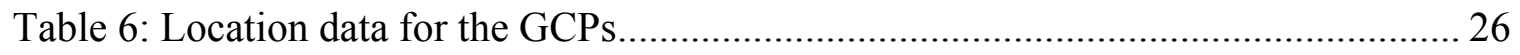

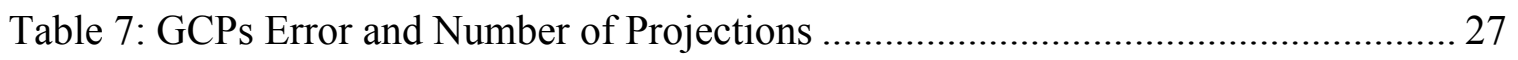

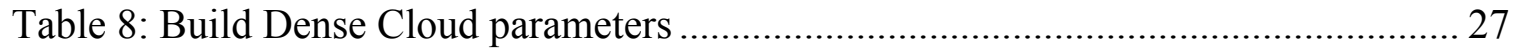

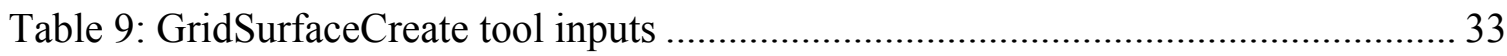

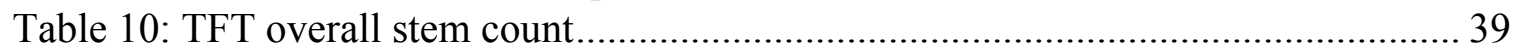

Table 11: Proportional Allocation TFT vs. UAV comparison results for 0-3 feet and 3-7

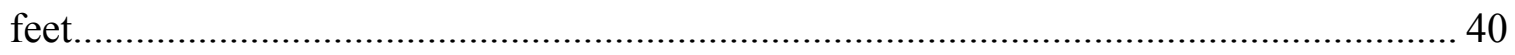

Table 12: Proportional Allocation TFT vs. UAV comparison results for $>7$ feet stems .. 41

Table 13: Proportional Allocation overall TFT vs. UAV results................................... 41

Table 14: Three closest transects averaged per area .................................................... 44

Table 15: Transects Averaged TFT vs. UAV comparison results for 0-3 feet and 3-7 feet

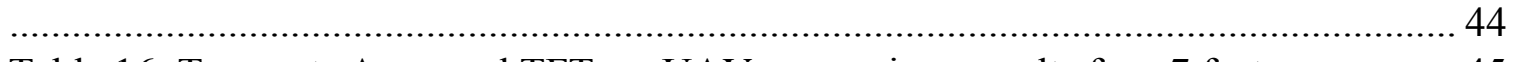

Table 16: Transects Averaged TFT vs. UAV comparison results for $>7$ feet ................. 45

Table 17: Transects Averaged TFT vs. UAV overall results........................................ 45

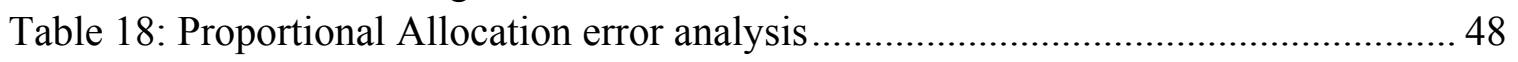

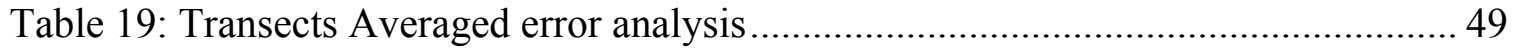




\section{Introduction}

Riparian zone vegetation plays a significant role in regulating stream and river water temperature. Some watershed restoration projects aim to protect, maintain, and restore fish and wildlife habitats along with water quality and quantity. A major challenge facing these efforts is the collection of timely, accurate, and cost-effective impact assessment data. Typically, enumerator based assessments require significant resources including funding, personnel, and time, and have methodological limitations. These include enumerator consistency and bias, geographical coverage, and a significant lag in data analysis compared to program implementation [1]. Together, these limitations affect the value of impact assessments and jeopardize the external validity and replicability of the interventions.

As various restoration strategies arise, rapid monitoring and response methods are needed to objectively and reliably justify and inform decision-making around such conservation projects. Recent research about riparian zone restoration has found that the monitoring process needs improvement to provide better quantitative evaluation of funded action efficiencies along with a detailed understanding of vegetation patterns [2]. These limitations inspired the effort to monitor riparian restoration projects using a commercially available Unmanned Aerial Vehicle (UAV) equipped with a GoPro camera. The ability of a UAV to provide high-resolution temporal data can help determine the success of environmental conservation programs. These efforts can ensure funds will be allocated in the most accountable and sustainable way. 
Remote sensing image acquisition and mapping technologies are rapidly developing with the advent of technologies and research involving UAVs. A small UAV equipped with an inexpensive camera can produce a high resolution, three-dimensional digital surface model (DSM) with accuracies in the order of 4-6 inches, while traditional techniques such as manned aircraft or satellite imagery typically have accuracies in the range of 8-20 inches [3]. UAV platforms can be purchased off-the-shelf ready for remote sensing applications and photogrammetric data acquisition. This is partly due to the technological advancement of miniature Global Positioning Systems (GPS) and inertial measurement unit (IMU), which consists of the accelerometer and gyroscope - the sensors used in the control system of the UAV. These advancements have contributed to the price drop in both quadcopter and fixed wing UAVs, leading to a rapid output of research about UAV applications in remote sensing. These applications are showing to be particularly promising for environmental monitoring, inventory and modeling purposes.

A photogrammetric technique called Structure from Motion (SfM) is used to create three-dimensional point clouds that are derived from digital images collected onboard UAVs, similar to the type of data produced by Light Detection and Ranging (LiDAR) technology. A point cloud created by LiDAR is a three-dimensional reconstruction of an area of interest made up of points containing data on the latitude, longitude, and altitude of each point. LiDAR is a remote sensing technology that calculates the distance to an object by taking the speed of light multiplied by the time it takes for an emitted laser to travel to an object [4]. LiDAR has been widely used for 
biomass inventory and estimation [5-7]. Since LiDAR point clouds have been proven to accurately estimate height, canopy cover, and locations of above ground biomass (AGB), this study uses methods developed for LiDAR point clouds and applies them to the UAVgenerated point cloud, at a fraction of the cost. A UAV mounted with an off-the-shelf digital camera is significantly less expensive than a LiDAR sensor either mounted on a UAV or manned airborne platform. The processing time and power required to manipulate LiDAR data are also substantially greater than that needed to process the photogrammetry data retrieved from the UAV $[8,9]$.

The Freshwater Trust (TFT) in Portland, OR is a conservation non-profit whose mission is to preserve and restore freshwater resources. TFT, along with the McKenzie Watershed Council and Upper Willamette Soil and Water Conservation District, has begun a riparian zone restoration project on the McKenzie River in order to restore river bank stabilization, changes in flood flows due to dams, and provide necessary shade to maintain a temperature in the river suitable for its wildlife. TFT planted 6,150 trees and plants of 22 different species in a 2.02-acre, 2,193-foot-long area along Cedar Creek, an offshoot of the McKenzie River, in Springfield, OR. This project was used to develop methods for UAV derived riparian restoration monitoring. 


\section{Background}

\subsection{Literature Review}

The technological development of UAVs and their ability to derive highresolution 3D-information at a much lower operational and up front cost compared to manned airborne platforms and satellite imaging has made UAV image acquisition appealing in several applications. Research applications utilizing UAVs for environmental monitoring, management, and evaluation have been explored significantly in the past ten years. The use of UAVs for data collection in natural resource $[10,11]$, biomass [2], forest [12-14], and vegetation [15, 16] monitoring have been found to have substantial impacts on the temporal and spatial resolution of data at a more cost effective price than traditional monitoring practices.

Although many studies have been conducted utilizing UAVs for mapping and monitoring purposes, there continues to be a vast array of questions and demand for additional research surrounding the subject. In a study by Fritz et al. in 2013, the potential use of UAVs as a platform for tree stem detection in open stands was analyzed. A UAV point cloud was generated and compared with a terrestrial laser scanner (TLS) point cloud of the same area. The tree stems reconstructed with the SfM point cloud were found to be far less accurate and complete than in the TLS point cloud, but the two were found to correlate well with a Pearson's correlation coefficient of $r=0.696$. The study concluded that there is high potential for UAV-based three-dimensional reconstruction of forest stands but states the need for additional research in vegetation stages, flight 
patterns and processing setup, which were all considered in the method development for this study [13].

Multiple platforms and methodologies have been implemented in various applications showing varying results when comparing UAV image acquisition to traditional remote sensing technologies. A study by Zarco-Tejada et al. in 2014 used a fixed wing UAV platform to acquire high resolution $(5 \mathrm{~cm} /$ pixel) imagery. The images were used to generate ortho-mosaics and digital surface models (DSMs) to assess canopy height of olive orchards in southern Spain. These results were compared to measurements taken with a Trimble R6 GPS receiver running in Real Time Kinematic (RTK) mode of 152 validation trees in the field. Residuals were defined as the difference between the actual tree heights measured and the tree heights estimated from the DSM. The coefficient of determination was found to be 0.83 , and the root mean squared error (RMSE) was 35 centimeters. The study reports that airborne laser scanners (ALS) produce similar results with RMSEs ranging from $9 \mathrm{~cm}$ to $120 \mathrm{~cm}$ depending on canopy type. The results show that a low cost camera-UAV system can create DSMs accurate enough for monitoring purposes at a much cheaper cost than LiDAR systems [14].

A major challenge facing riparian restoration projects is the ability to assess largescale vegetation semi-automatically in terms of species, cover, volume, structure, and biomass. Dufour et al. in 2013 attempted to tackle these challenges with a study that compared UAV photogrammetry with LiDAR and radar data collected from riparian restoration project areas in northwestern France. The results showed that to be able to discriminate between species in various riparian corridors it would be necessary to fuse 
the data from very high resolution images and LiDAR. The study also concluded that UAV paired image analysis would not be a way to replace field work, but instead could augment the data collected in the field to provide a complete evaluation, especially in large-scale studies.

In respect to riparian zone monitoring, UAVs can provide a unique advantage because the identification of smaller vegetation features requires high resolution imagery, which can easily be obtained by a low altitude set of photographs. In a study by Dunford et al. 2009, the potential and constraints of UAV technology for the characterization of Mediterranean riparian forests was analyzed. Although the area of interest was large and the image density small, vegetation units could be classified with an accuracy of Kappa = 0.79. Kappa shows the agreement between two data sets with a correction for expected agreement. The primary constraints resulted from navigating illumination conditions and sensor movement during flight that caused variations in spatial resolution. The study discussed the lack of work that has been done in investigating the application of UAV technology used to map vegetation health in riparian forests. There are many challenges and opportunities surrounding the investigation of UAV technology to aid riparian management, but Dunford et al. assert that the potential for the technology to provide high-resolution map products rapidly with much more flexibility than conventional practices has been proven [17].

The 3D point cloud created from photos collected via the UAV is built using SfM algorithms. SfM uses feature matching on a set of images to reconstruct the 3D geometry of the static scene depicted in the images [18]. The low-cost of a UAV paired with a 
consumer camera is supplemented with the inexpensive processing SfM provides for high-resolution topographic reconstruction. This makes the complete system and methodology ideal for low budget research in remote areas. In a study conducted by Westoby et al. in 2012, SfM photogrammetry is outlined as a "revolutionary, low-cost, user-friendly, photogrammetric technique for obtaining high-resolution datasets at a range of scales" [18]. A method is presented using SfM to create high resolution digital elevation models (DEMs) from photos obtained using a consumer grade digital camera. The SfM DEMs are compared to terrestrial laser scanner models. The results show SfM produces decimeter-scale vertical accuracy even in sites with complex terrain. The authors of this study reiterate a need for lower cost remote sensing technology to lower the high capital and logistical costs associated with high-resolution topographic surveys.

The point cloud created from the UAV and SfM algorithms is the same format as a point cloud created by LiDAR, thus the same techniques used on LiDAR point clouds to locate and measure biomass can be utilized on the SfM point cloud. In 2011 Edson and Wing analyzed the ability of LiDAR to accurately measure and locate tree stems using three different software packages. The software programs were FUSION, TreeVaW, and watershed segmentation using ArcGIS. The LiDAR data was compared to field measurements collected from 11 plots in the Oregon State University McDonald-Dunn Research forest. Data was collected for species, height, crown width, diameter at breast height (DBH) for stems with diameters greater than 13 centimeters, and diameter at ground level (DBA) for stems with diameters less than 13 centimeters, that are taller than one meter [7]. The study showed that LiDAR estimations using FUSION to analyze 
above ground biomass led to an underestimation of 25\%, using TreeVAW resulted in an underestimation of $31 \%$, and watershed segmentation showed an overestimation of approximately $10 \%$. The abundance of research surrounding LiDAR and UAV biomass estimation shows the potential for promising results, but questions remain surrounding analysis and methodology techniques. 


\section{Objective}

The aims of this study were to develop a method for UAV derived riparian restoration monitoring and compare it to traditional ground-truthing methods for analysis of efficiency, resolution, and effectiveness. The goal is to assess whether a small, inexpensive UAV mounted with a GoPro camera can provide data accurate enough for the validation of a riparian restoration project by comparing the data to TFT's enumerator collected data. In this study, a quadcopter UAV was used to acquire photogrammetric data of the 2.02-acre riparian zone being restored by TFT using a GoPro camera. The images were input into Agisoft PhotoScan, a software that performs photogrammetric processing of digital images using feature matching and SfM, a computer vision technique. SfM matches features on a set of images to reconstruct the camera motion and 3D geometry of the static scene depicted in the images [19]. Three-dimensional point clouds were created from the processed images and scaled to the correct size and elevation using Ground Control Points (GCPs) for reference. GCPs are points placed evenly throughout the area of interest that are georeferenced using 10 centimeter accurate GPS technology. The dense point cloud was then used to create a comprehensive digital elevation model (DEM). The DEM created from the UAV was evaluated to determine the quantity and size of planted biomass. The biomass inventory was compared the monitoring data recorded from TFT enumerators and assessed for its accuracy to conclude the feasibility of utilizing the most efficient option, photo collection via UAV quadcopter, for riparian restoration monitoring. 


\section{Project Background and Design}

TFT is a non-profit conservation organization whose mission is to restore

freshwater resources. TFT's Riparian Restoration Project Cedar Creek 2.5 (“Cedar Creek Project") is located on private property north of Springfield, OR and consists of 2.02 acres along 2,193 linear feet of stream situated on the Southern bank of the North Branch of Cedar Creek. The aquatic and riparian habitats in this lower portion of Cedar Creek have been characterized as highly impacted by agricultural, residential, commercial, and industrial land use as well as historical channelization and impoundment of the river. This use has caused much of the riparian vegetation in this section of the river to be altered, severely reduced in size, or eliminated [20]. Non-native species such as Himalayan blackberry and reed canary grass were dominating the riparian areas on the project site, inhibiting nearly all natural regeneration of native vegetation. To restore the riparian area on the Cedar Creek Project site TFT's objective is to establish a native riparian buffer along the south bank of Cedar Creek to provide long-term shade to the water, enhance fish and wildlife habitat, and improve riparian function. The project was separated into three phases: site preparation, active planting, and plant establishment. Site preparation consisted of managing the reed canary grass and Himalayan blackberry present on the site. The planting area and project site is shown in Fig. 1. 


\section{Cedar Creek RM 2.5 - Planting Area}

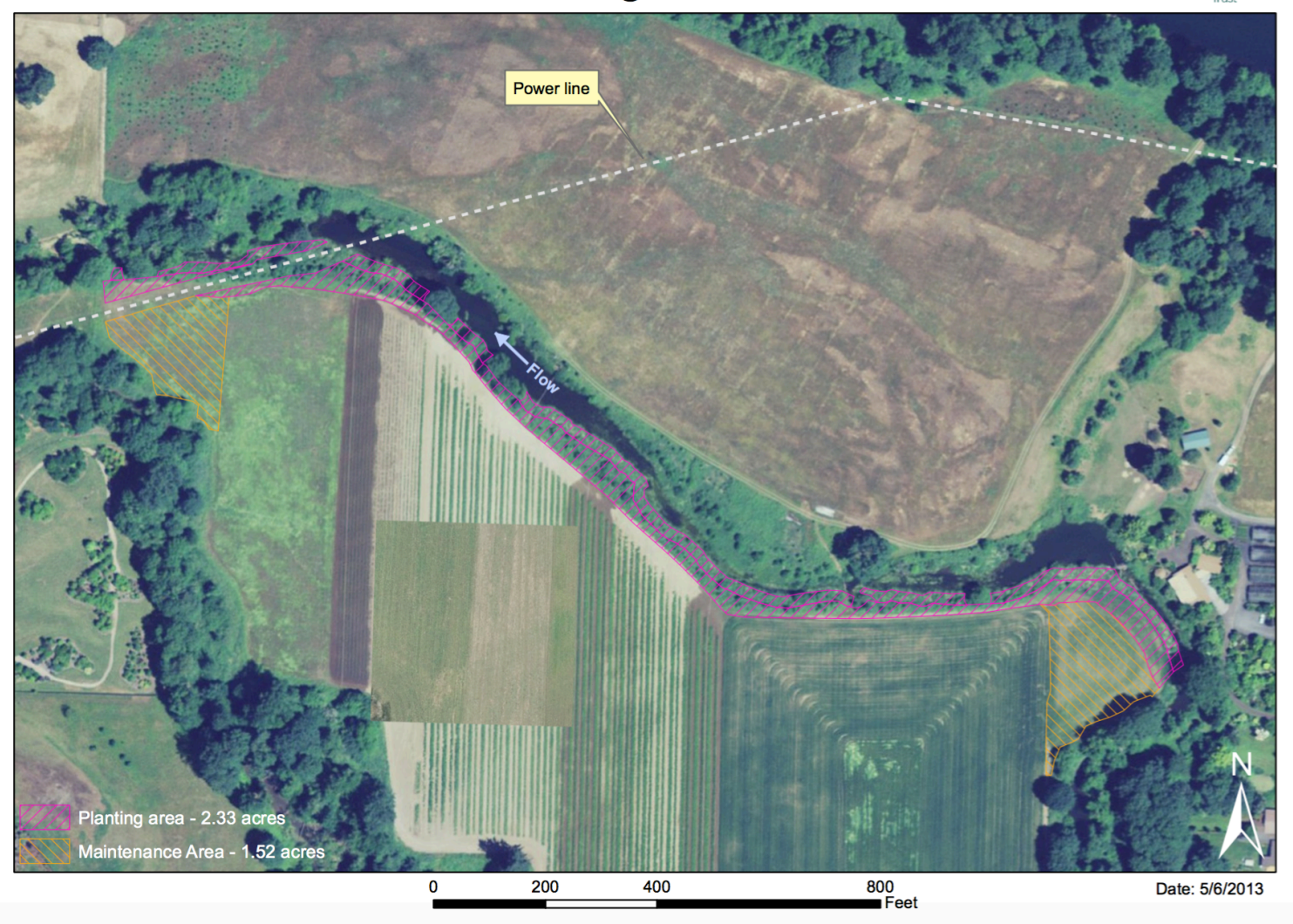

Figure 1: Cedar Creek Planting Area [21]

The Cedar Creek Project earns salable credits under the Environmental Projection Agency's Clean Water Act authority for impacting stream temperature. As the project

meets the required standards (Fig. 2), a number of credits are established and can be sold through ecosystem service markets, generating revenue that can be leveraged into further restoration efforts. Site restoration began in Fall 2014 with chemical and mechanical treatment to remove reed canary grass and Himalayan blackberry. Tree protection caging was also installed on a selection of existing conifers. 6,150 locally sourced native trees and shrubs were planted in winter of 2015. The approximate density of the plants is 3,000 stems per acre. 


\begin{tabular}{|c|c|}
\hline Metric & Standard \\
\hline average native woody stems/acre & $\begin{array}{l}\text { minimum } 1,600 \text { native woody stems/acre (or density as } \\
\text { guided by reference sites) at end of year } 5\end{array}$ \\
\hline number of woody species & $\begin{array}{l}\text { minimum } 5 \text { species; no single species may comprise } \\
>50 \% \text { of woody plants at end of year } 5\end{array}$ \\
\hline$\%$ total native stems that are shrubs or trees & $\begin{array}{l}\text { minimum of } 20 \% \text { of total stems/acre, respectively at end } \\
\text { of year } 5\end{array}$ \\
\hline
\end{tabular}

Figure 2: Performance standards for water quality trading riparian vegetation projects [22]

The objective of the Cedar Creek Project is "to establish an ecologically functioning native riparian forest with species composition, species diversity and canopy structure informed by reference site conditions and best professional judgment," [20]. The future conditions of the project site will include a multi-storied canopy and a thick under story of multi-stemmed shrubs.

\subsection{The Freshwater Trust Monitoring Procedures and Techniques}

TFT has established a Revegetation Monitoring Protocol to track the progress of the Cedar Creek Project toward the achievement of the performance standards and assess revegetation effectiveness to help guide future projects. Monitoring of the project will occur annually for the first five years after the project is installed and then repeated every five years through year 20, when the life of the credits has expired. The planting area is defined as the entire area from which water quality credits can be generated.

The monitoring process begins in Year 1 by establishing transects during the first round of surveys. The transects originate at a randomly generated point location that is permanently mounted in the ground with rebar where it is capped and flagged. The transects are oriented perpendicular to the stream with the inland edge centered on each GIS-generated point. Two twenty by twenty feet square plots are established along each 
side of the transect line (Fig. 3). The transect profiles are set up the same way every year to detect change. The monitoring protocol establishes that seven transects are created for every two acres of planting area to ensure the sampling intensity meets a target of $5 \%$ of the planting area. Two additional transects will be generated in addition to the original seven to provide flexibility when monitoring to avoid locations that do not represent the area correctly or are unsafe to monitor.

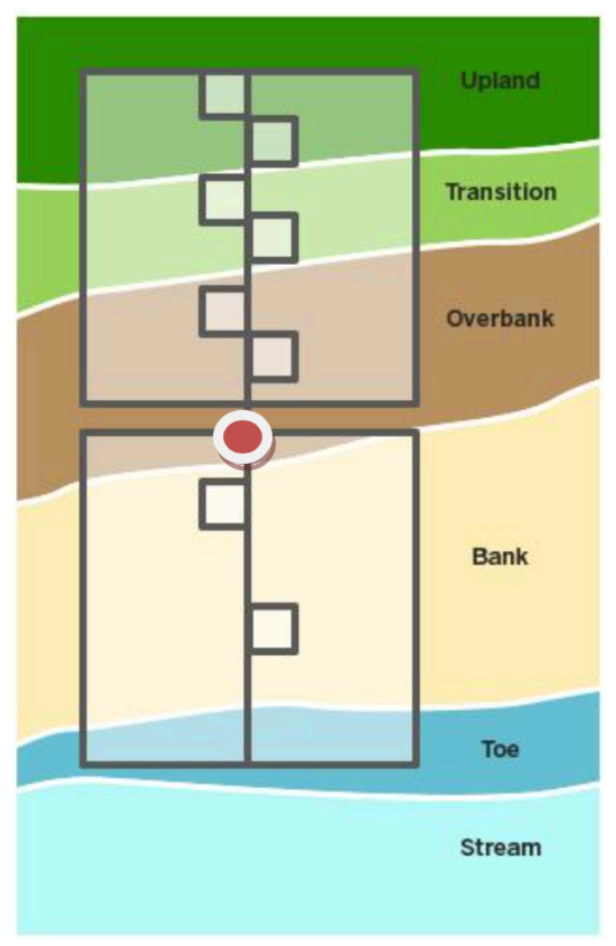

Figure 3: Revegetation monitoring transect layout [22]

Once the transects are established, enumerators begin the survey by creating a Transect Narrative. The Transect Narrative consists of recording data on features in the immediate vicinity of the transect. These features consist of nearby canopy cover and vegetation that existed before the project plantings, naturally recruited native vegetation, soils characteristics, standing water, invasive species cover, cover and height of vegetation competing with plantings, wildlife sightings, browse damage, observations or 
installed plant vigor or growth, and management suggestions. The location of each hydrological zone (Fig. 4) is recorded by measuring their distance from the origin of the transect. The shade in the transect impacting the stream temperature is measured using a Solar Pathfinder. These measurements are taken at the center of the stream so they are compatible with outputs of GIS shade models. The shade is only recorded on years 1, 5, 10,15 , and 20 . The last portion of the transect profile is photo documentation of the transect. A photo is taken from the transect origin in the direction of the water and any unique features observed are also recorded with photo documentation.

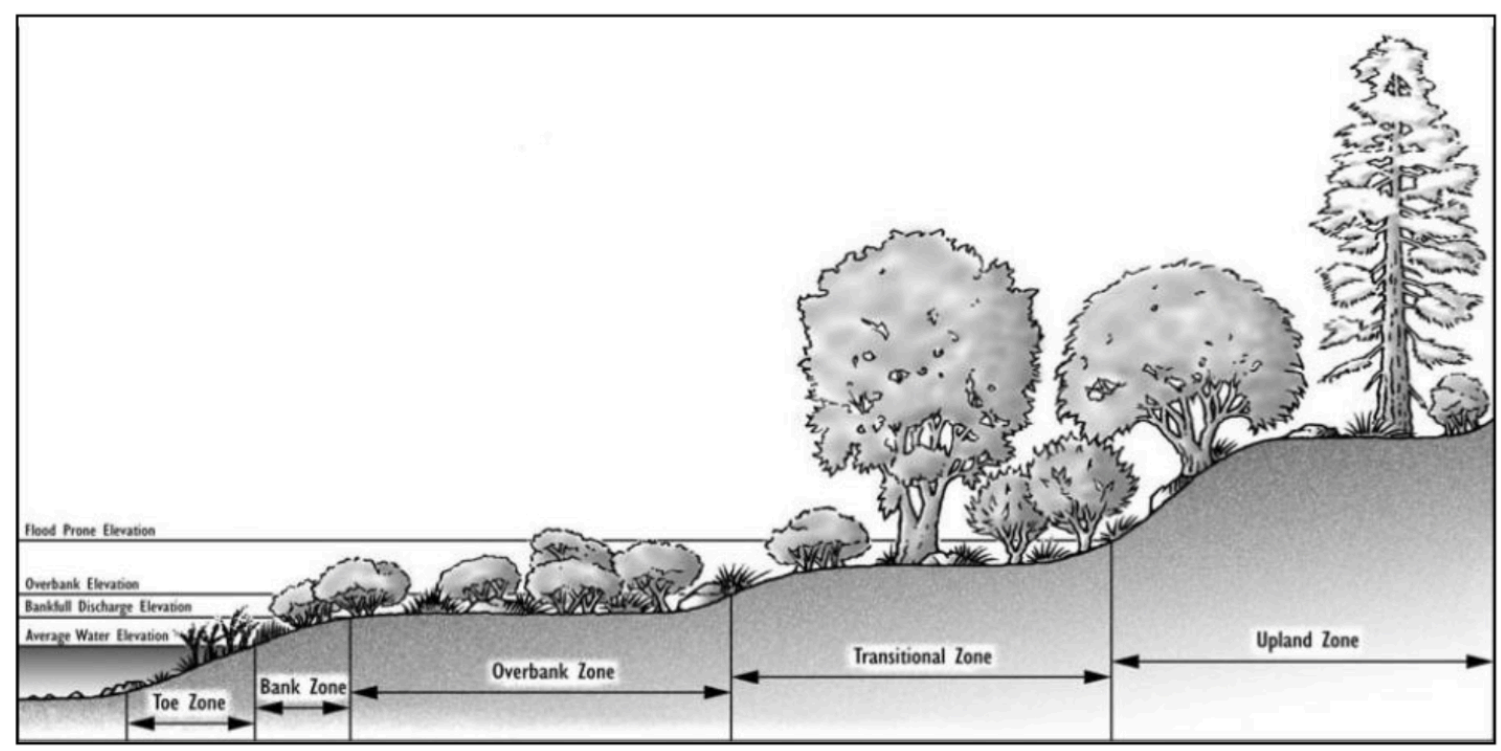

Figure 4: Hydrological zone boundaries in a riparian area [22]

In each separate hydrological zone all non-invasive woody trees, shrubs and vines standing taller than 6 inches are tallied in each transect. They are classified by their species and height class. The height classes are differentiated by plants that are 6 inches 3 feet, 3-7 feet, and greater than 7 feet. All trees and snags with diameter at breast height 
(DBH) larger than 5 inches will have their diameters recorded into separate classes of 510 inches, 10-15 inches, 15-21 inches, and greater than 21 inches. The canopy cover is measured using a spherical densiometer.

Two 1 meter x 1 meter ( 3.28 feet x 3.28 feet) subplots are randomly established in each hydrological zone, one on each side of the transect centerline. The percent cover of herbaceous species and invasive woody species are estimated in each subplot. The percent cover is visually estimated to the nearest $5 \%$.

A running list of all plant species in and around the planting area are compiled during the entire monitoring process. The plants will be characterized as native or introduced, whether they are considered an invasive species, and whether they are dominant. Dominant plants have cover greater than $20 \%$ while subdominant plants have cover between 10 and $20 \%$. 


\section{Methods and Materials}

\subsection{Technology/Platform}

A 3D Robotics Solo quadcopter (Fig. 5) was the UAV used for this study. The Solo is 10 inches tall and 18 inches from motor to motor. A lithium polymer rechargeable battery provides a maximum flight time of approximately 25 minutes with a range of 0.5 miles, limited by the payload, ambient conditions, and flight style. The maximum payload the Solo can handle is $0.92 \mathrm{lbs}$. The quadcopter has four brushless $880 \mathrm{kV}$ motors, two that spin clockwise and two that spin counterclockwise. Each motor is controlled by an Electronic Speed Controller (ESC) that regulates the speed of each based on the input from the various sensors and output of the autopilot. The speeds are varied based on the need for change in the pitch, roll, and yaw axes. The motors rotate 10-inch glass-reinforced nylon propellers.

The processor that controls the autopilot on the Solo is a Pixhawk 2 which runs ArduPilot Copter software. This processor has four sensors that calculate Solo's orientation and motion in flight:

1. ST Micro L3GD20 3-axis 16-bit gyroscope

2. ST Micro LSM303D 3-axis 14-bit accelerometer / magnetometer

3. Invensense MPU 6000 3-axis accelerometer/gyroscope

4. MEAS MS5611 barometer

The inputs from these sensors are processed in the Pixhawk with an ARM Cortex-M4 STM32F427 with 2MB of flash memory and $256 \mathrm{~KB}$ of RAM.

The Solo's controller has its own WiFi connection which enables a connection to a mobile device or computer [23]. 


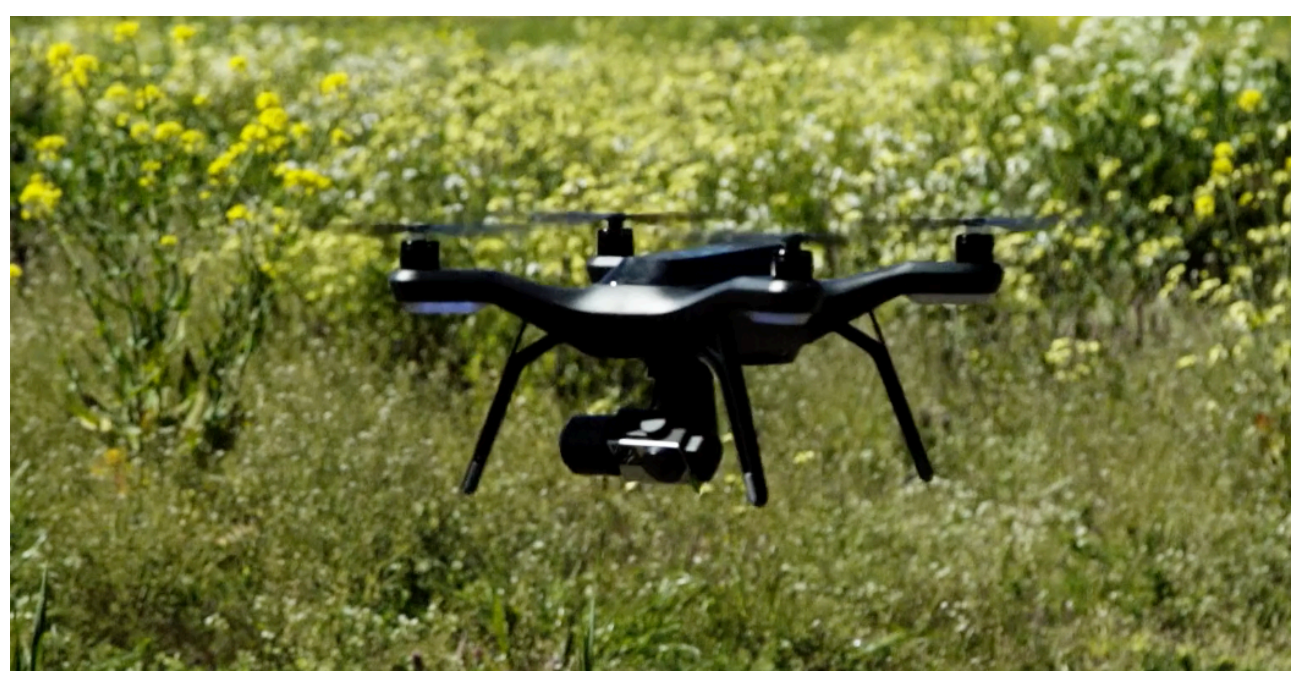

Figure 5: 3DR Solo

\subsection{Flight and Photo Processing Procedure}

The flight preparations begin with assessing the area of interest. The 2.02-acre

project site was divided into 2 separate areas for a total of 4 flights. The areas are shown in Fig. 6. The areas were sized based on flight time. Since the battery on the UAV allows a maximum flight time of 25 minutes, all flights were kept under 20 minutes. 


\section{Cedar Creek RM 2.5 - Planting Area}

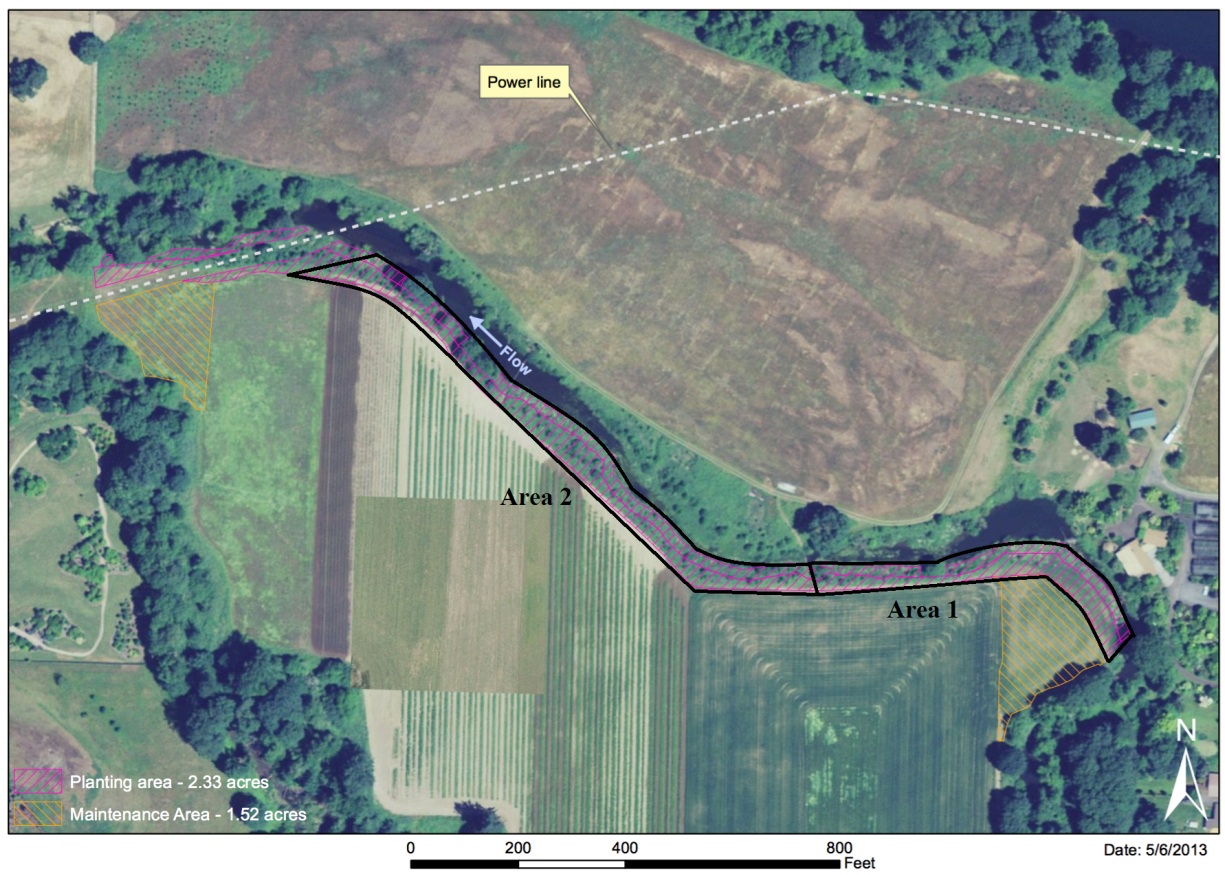

Figure 6: Flight areas

Once the site is divided into flight areas, the flights can be planned using Mission Planner (http://ardupilot.org/planner/index.html) flight plan software. A polygon is first drawn around the flight area, then the Survey (Grid) tool is used to calculate the correct placement of waypoints. Waypoints are GPS points with longitude, latitude, and altitude that direct the UAV's autopilot. A flight is flown both perpendicular and parallel to the river in each area. In the Survey (Grid) tool the camera specifics, flight angle, flight speed, photo overlap percentage and photo sidelap percentage are input to calculate a flight path. The input parameters are shown in Table 1. Photo overlap percentage is obtained by collecting a specified number of photos/second at a particular flight speed. For example, 2 photo/second with the UAV flying at $16.4 \mathrm{ft} / \mathrm{s}$ was used to achieve $80 \%$ overlap. The distance between parallel flight lines was calculated in Mission Planner to 
produce $80 \%$ sidelap based on the field of view of the GoPro. The flight polygons and flight paths for each area are shown in Fig. 7 and Fig. 8.

Table 1: Mission planner inputs

\begin{tabular}{|l|r|}
\hline Focal Length [in] & 0.20 \\
\hline Image Width [pixels] & 2800 \\
\hline Image Height [pixels] & 2100 \\
\hline Sensor Width [in] & 0.17 \\
\hline Sensor Height [in] & 0.13 \\
\hline Overlap [\%] & 80 \\
\hline Sidelap [\%] & 80 \\
\hline Overshoot [ft] & 16.4 \\
\hline
\end{tabular}

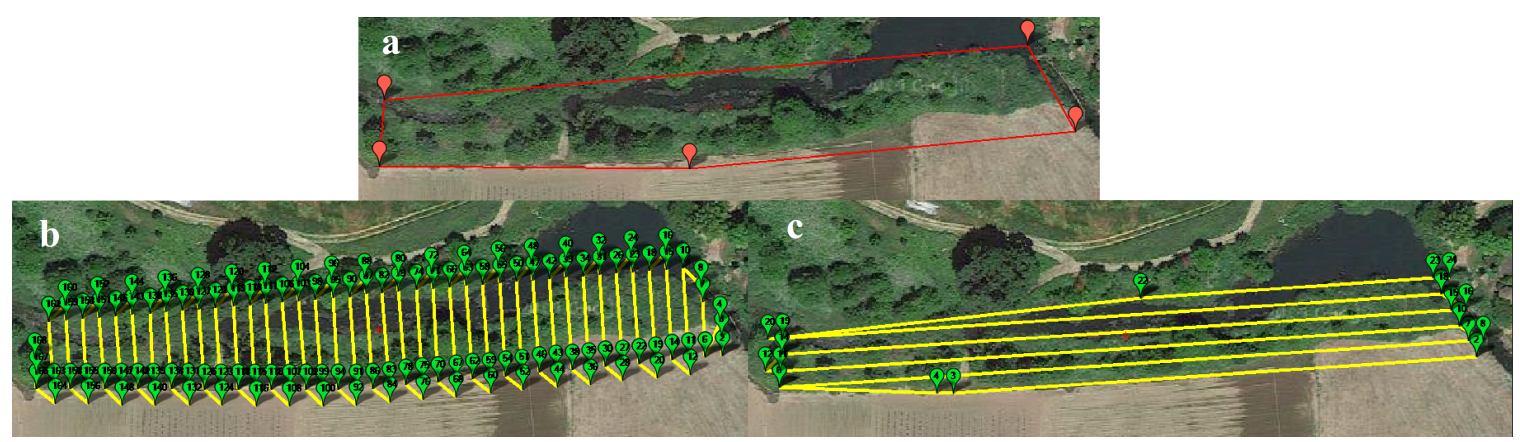

Figure 7: Flight area 1 a) Polygon drawn around area of interest b) Flight path flown perpendicular to area of interest, flight angle $=176^{\circ} \mathrm{c}$ ) Flight path flown parallel to the area of interest, flight angle $=86^{\circ}$ 


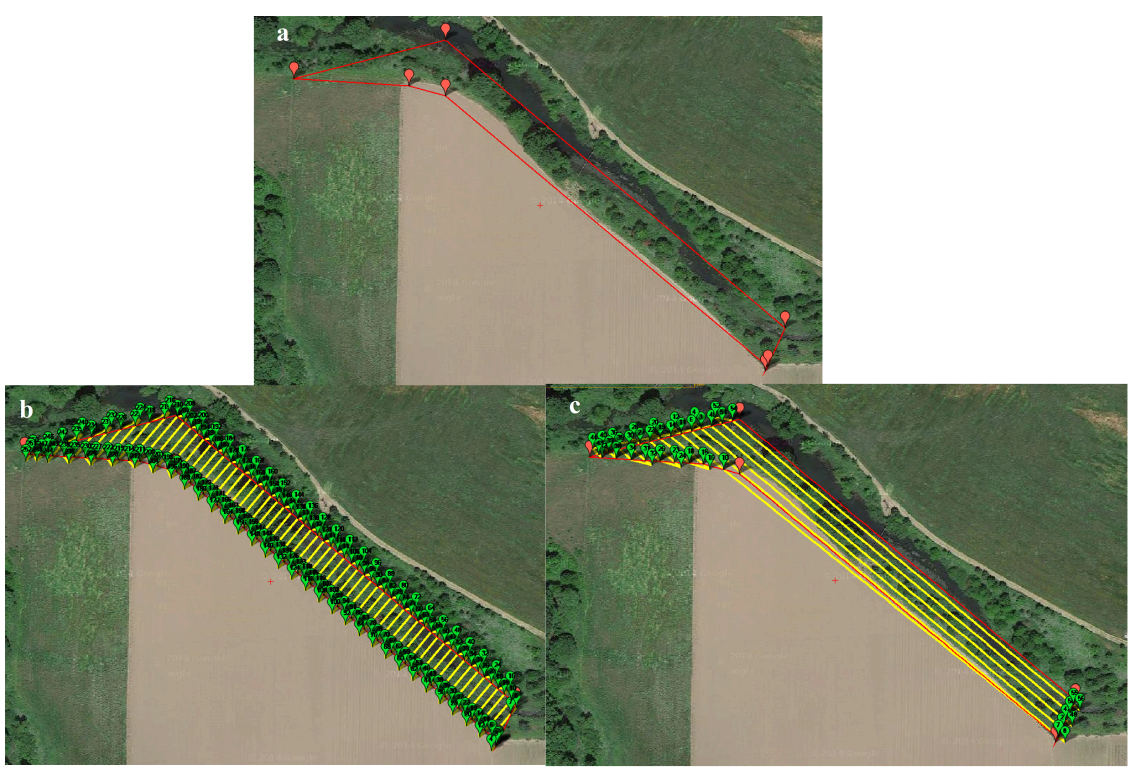

Figure 8: Flight area 2 a) Polygon drawn around area of interest b) Flight path flown perpendicular to area of interest, flight angle $=220^{\circ} \mathrm{c}$ ) Flight path flown parallel to area of interest, flight angle $=$ $130^{\circ}$

Before each flight, 10 ground control points (GCPs) were laid down in areas easily viewed by the UAV while in flight. GCPs were marked by $4 \times 4$ foot black and white vinyl sheets that present a clear center point. The latitude, longitude, and altitude were taken at the center of each GCP with a Trimble GeoExplorer 6000 Series GNSS receiver in unprojected WGS 1984 coordinate system. This GNSS receiver has decimeter accuracy. A GCP with the GNSS receiver is shown in Fig. 9. The placement of the GCPs in shown in Fig. 10. 


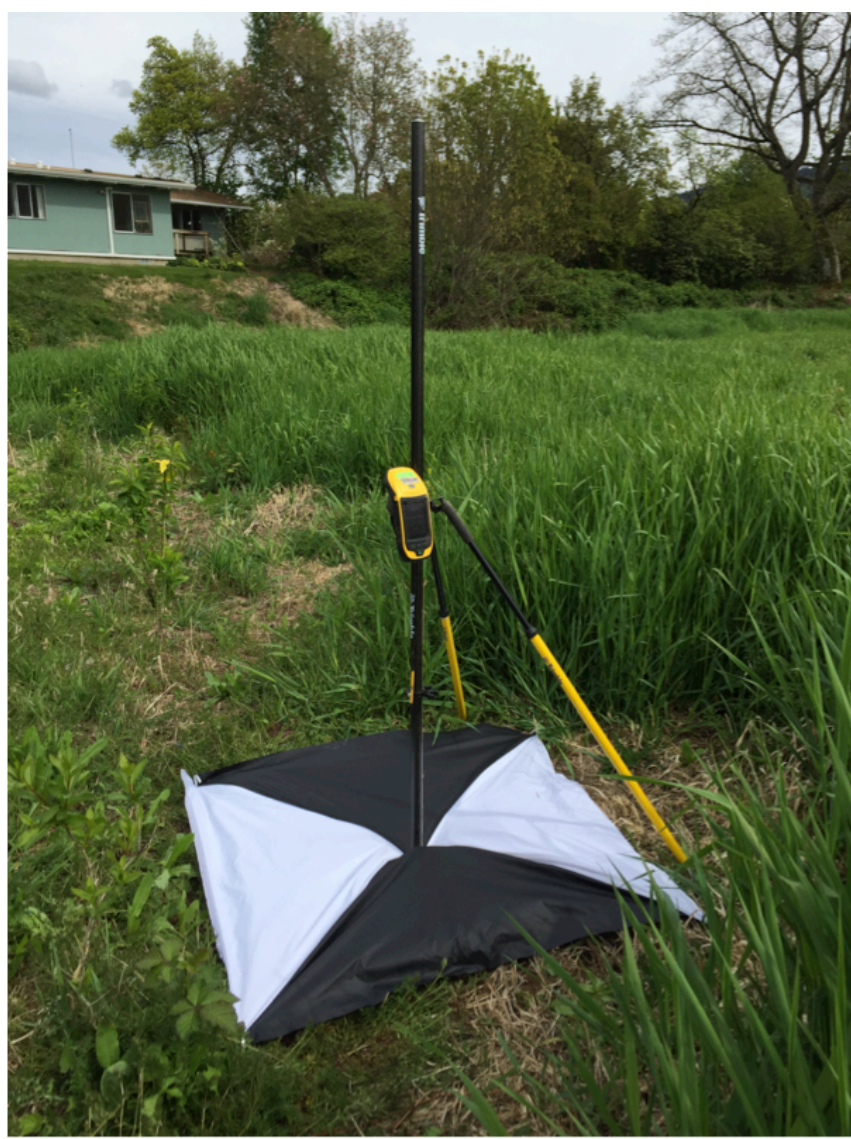

Figure 9: GCP with Trimble GeoExplorer 6000 Series GNSS receiver 


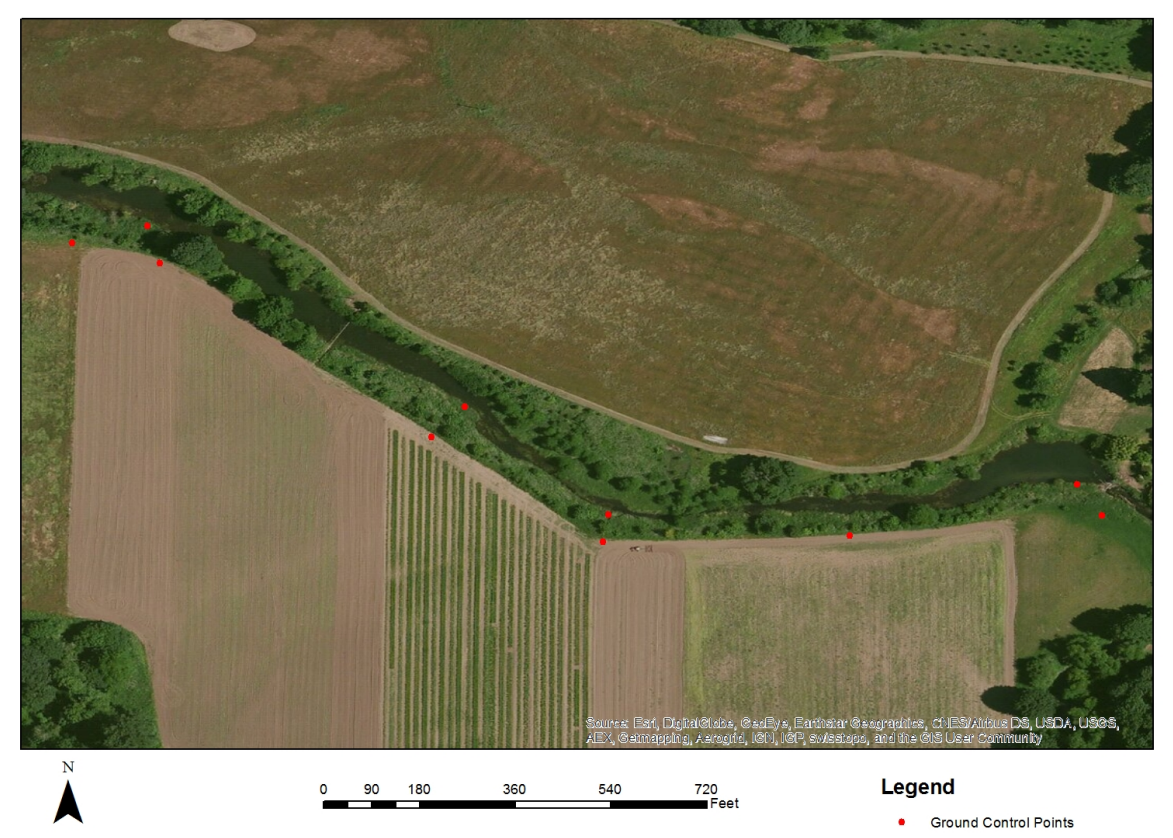

Figure 10: Placement of GCPs

A checklist was used to account for all components needed for flight day. All batteries needed to be charged to $100 \%$ before leaving for the field. Once in the field after GPS coordinates are taken at each GCP, the UAV is placed in a position where it has a clear view of the sky and can easily access GPS. Once the UAV is turned on and connected to GPS, Mission Planner can connect to the UAV via the Solo Wifi. The flight can then be uploaded from Mission Planner using the "Write WPs" option. This sends the flight plan from the program to the UAV. The flight plan is then sent from the UAV to a Window's digital portable device and uploaded to the program Tower (https://play.google.com/store/apps/details?id=org.droidplanner.android) through the Solo Wifi. Tower is then used to control the UAV. Before the flight begins, the GoPro is turned on and the settings are selected as shown in Table 2. The gimbal that mounts and steadies the GoPro is set to $45^{\circ}$ with respect to the horizontal. The command prompt in 
Tower begins the flights. After each flight is completed, the photos are loaded onto the computer and the SD card is cleared to ensure there is room for more photos. The details from the flights are recorded. The details, listed in Table 3 and Table 4, were recorded for each flight. The flight times ranged from approximately 7-15 minutes.

Table 2: GoPro Settings. The first attempt at processing the photos indicated that the original data collection had resulted in double the amount of data needed for an accurate reconstruction. Half of the images were deleted, only one photo per second was required to achieve $80 \%$ overlap.

\begin{tabular}{|c|c|}
\hline Parameter & Selection \\
\hline Long Exposure & 2 photo/second \\
\hline Resolution & $12 \mathrm{MP}$ \\
\hline Width & Wide \\
\hline
\end{tabular}

Table 3: Flight details 1

\begin{tabular}{|l|l|l|l|l|l|l|l|}
\hline Flight No. & Area & $\begin{array}{c}\text { Path } \\
\text { Direction }\end{array}$ & $\begin{array}{c}\text { Photo } \\
\text { Frequency } \\
{[\mathbf{s e c}]}\end{array}$ & $\begin{array}{c}\text { Gimbal/ } \\
\text { Camera } \\
\text { Angle } \\
\text { [degrees] }\end{array}$ & Lighting & $\begin{array}{l}\text { Start } \\
\text { Time }\end{array}$ & End Time \\
\hline 1 & 1 & EW & 0.5 & 45 & sun & $1: 14: 35$ & $1: 21: 40$ \\
\hline 2 & 1 & NS & 0.5 & 45 & sun & $1: 34$ & $1: 45: 32$ \\
\hline 3 & 2 & EW & 0.5 & 45 & sun & $2: 54: 57$ & $3: 04: 50$ \\
\hline 4 & 2 & NS & 0.5 & 45 & $\begin{array}{l}\text { sun, } \\
\text { slightly } \\
\text { windy }\end{array}$ & $3: 17: 29$ & $3: 32: 56$ \\
\hline
\end{tabular}

Table 4: Flight details 2

\begin{tabular}{|l|l|l|l|l|l|l|}
\hline $\begin{array}{c}\text { Duration } \\
\text { [min] }\end{array}$ & $\begin{array}{c}\text { Battery } \\
\text { Name }\end{array}$ & $\begin{array}{c}\text { Battery } \\
\text { at Start } \\
{[\%]}\end{array}$ & $\begin{array}{c}\text { Battery } \\
\text { at End } \\
{[\%]}\end{array}$ & $\begin{array}{c}\text { Battery } \\
\text { Duration } \\
{[\%]}\end{array}$ & \# of Photos & Notes \\
\hline $0: 07: 05$ & OSU1 & 69 & 45 & 24 & 819 & 1 vulture \\
\hline $0: 11: 32$ & FH1 & 94 & 26 & 68 & 1090 & 1 tractor \\
\hline $0: 09: 53$ & BD1 & 96 & 41 & 55 & 905 & 1 raptor \\
\hline $0: 15: 27$ & FH2 & 93 & 4 & 89 & 1428 & $\begin{array}{l}\text { not able to complete } \\
\text { full flight due to loss } \\
\text { of battery }\end{array}$ \\
\hline
\end{tabular}




\subsection{Post-flight image processing}

The photos were first inspected to eliminate any out of focus or off-site photos, then loaded into LightRoom (http://www.adobe.com/products/photoshop-lightroom.html) to remove the fisheye effect caused by the lens of the GoPro. The edges of the photos were cropped to remove any distortion. Agisoft PhotoScan was used to process the images acquired by the UAV in order to create a comprehensive 3D reconstruction of the riparian zone. The photos were loaded into Photoscan by Chunks. Chunks, as they are called in Photoscan, allow the software to perform a program on a limited number of photos to restrict the amount of processing power required. Each area was divided into two Chunks, one for each flight direction in the corresponding area, parallel and perpendicular. The filtered set of images was then masked in Photoscan to eliminate data that is not included in the project site.

Once the photos were loaded and masked in their respective chunks, they were aligned using SfM algorithms built into PhotoScan. SfM uses the Scale Invariant Feature Transform (SIFT) object recognition system to recognize and match features in multiple images in order to create a high resolution topographic reconstruction [18]. PhotoScan is able to detect these features by creating "keypoints" that are constant throughout the photo series even under viewpoint and lighting variations. Each keypoint is assigned one or more orientations based on local image gradient directions. The orientation combined with the scale of each keypoint generates a descriptor that is used to detect correspondences across the photos [24]. These keypoint descriptors are input into a 
bundle adjustment system that is used to estimate camera locations and create a sparse point cloud.

Table 5: Photoscan photo alignment parameters
\begin{tabular}{|c|c|}
\hline Parameter & Selection \\
\hline Accuracy & High \\
\hline Pair Selection & Disabled \\
\hline Key Points & 70,000 \\
\hline Tie Point Limit & 3,000 \\
\hline
\end{tabular}

The Photo Alignment command in PhotoScan presents four parameters. The selections for these parameters are shown in Table 5. When the accuracy setting is set to High, Photoscan uses the full resolution of the photo, Medium setting uses $50 \%$ of the photo resolution, and Low setting uses $25 \%$ of the resolution. The Pair Selection parameter has three options: disabled, reference, and generic. Pair selection "disabled" allows for the highest accuracy of alignment. "Reference" pair selection option requires photos to be geotagged with their location at the time they were taken. The GoPro does not geotag the photos so this option was not relevant to the study. "Generic" pair selection selects overlapping pairs of photos by matching photos using lower accuracy settings first, this option requires less processing but is less accurate. The Key Point Limit is the maximum number of points Photoscan will extract from each photo. The default value of 40,000 was increased to 70,000 points to allow a higher number of points extracted. The Tie Point Limit extracts the most accurate 3,000 points from the 70,000 tie points from each photo. The 3,000 tie points are then used in the alignment calculations. 1,835 out of 1,971 photos were aligned. The photos that were not aligned may have been out of focus or did not contain enough tie points for accurate calculation. 
Once the photos are aligned, the GCP data is imported into Photoscan in the Reference Pane under "Markers" (Table 6). Point 4 was omitted because the uncertainty was greater than the threshold $(>10 \mathrm{~cm})$. Point 1 was at the same location as Point 7 , so Point 1 was also omitted. GCPs are then manually placed by their Point ID in each photo where they are visible.

Table 6: Location data for the GCPS

\begin{tabular}{|l|l|l|l|l|}
\hline Point ID & \multicolumn{1}{|c|}{$\begin{array}{c}\text { GNSS } \\
\text { Height } \\
\text { [feet] }\end{array}$} & $\begin{array}{c}\text { Standard } \\
\text { Deviation }\end{array}$ & Latitude & Longitude \\
\hline 1 & 154.1 & 0.007977 & 44.05756335 & -122.9015674 \\
\hline 2 & 155.2 & 0.024969 & 44.05910108 & -122.9043043 \\
\hline 3 & 155.4 & 0.018649 & 44.05899761 & -122.9038531 \\
\hline 4 & 153.1 & 0.128101 & 44.05918879 & -122.9039156 \\
\hline 5 & 155.9 & 0.013392 & 44.05810266 & -122.9024543 \\
\hline 6 & 152.5 & 0.014507 & 44.05825939 & -122.9022796 \\
\hline 7 & 154.1 & 0.010255 & 44.05756355 & -122.9015679 \\
\hline 8 & 152.9 & 0.010221 & 44.05770215 & -122.9015406 \\
\hline 9 & 154.1 & 0.013228 & 44.05759265 & -122.900296 \\
\hline 10 & 154.1 & 0.011789 & 44.05769658 & -122.8989986 \\
\hline 11 & 153.0 & 0.006924 & 44.05785786 & -122.8991266 \\
\hline
\end{tabular}

Once the GCPs are added and manually placed in each photo, the camera alignment can be optimized by generating camera calibration based on the GCP locations. The errors of each GCP can then be observed (Table 7). The errors are the sum of the root square error in each direction, latitude, longitude, and altitude. 
Table 7: GCPs Error and Number of Projections

\begin{tabular}{|l|l|l|}
\hline GCP & Error $[\mathbf{m}]$ & $\begin{array}{l}\text { Number of } \\
\text { Projections }\end{array}$ \\
\hline 2 & 0.045 & 490 \\
\hline 3 & 0.055 & 461 \\
\hline 5 & 0.021 & 295 \\
\hline 6 & 0.012 & 256 \\
\hline 7 & 0.045 & 338 \\
\hline 8 & 0.066 & 291 \\
\hline 9 & 0.035 & 245 \\
\hline 10 & 0.012 & 126 \\
\hline 11 & 0.010 & 147 \\
\hline
\end{tabular}

With the photos aligned to build a sparse point cloud and the GCPs placed, a dense point cloud can be built using the Build Dense Cloud option. The reconstruction parameters are shown in Table 8. A High quality reconstruction was achieved with 48 GB of RAM on a remote server; an Ultra High quality reconstruction could be completed if more processing power was available. In order to create a dense point cloud, Photoscan calculates depth maps for every image. Out of focus images or poor texture on objects in the images can cause outliers in the points that make up the depth maps. Since the terrain of the project site is complex with many small details, Mild depth filtering was used to ensure important features were not sorted out.

Table 8: Build Dense Cloud parameters
\begin{tabular}{|c|c|}
\hline Parameter & Selection \\
\hline Quality & High \\
\hline Depth Filtering & Mild \\
\hline
\end{tabular}

Building the dense point cloud is the most processing intensive step and took several hours to process each chunk. Once each chunk had finished processing they were merged using the Merge Chunks option, which combines each chunk based on the 
overlapping markers. All the chunks merged to a complete point cloud, shown in Fig. 11 with detail shown in Fig. 12.

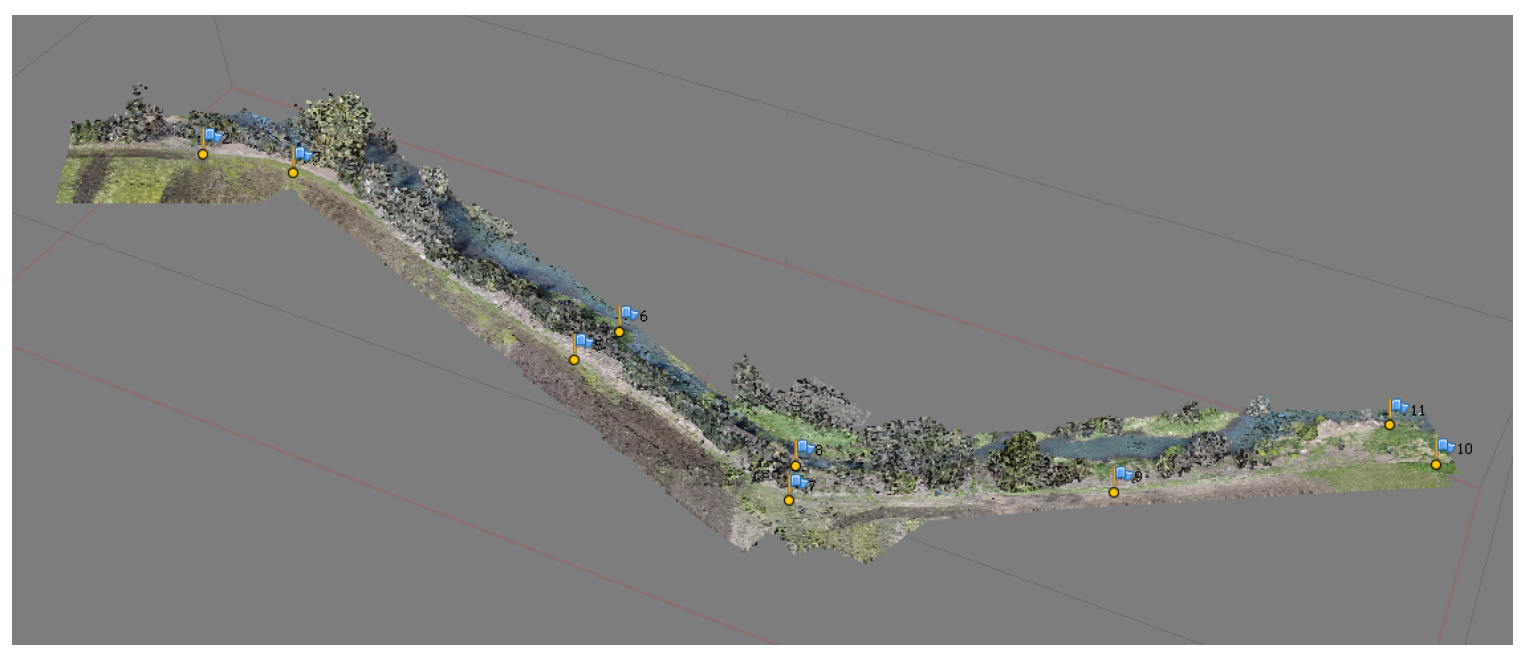

Figure 11: Complete point cloud of entire project site

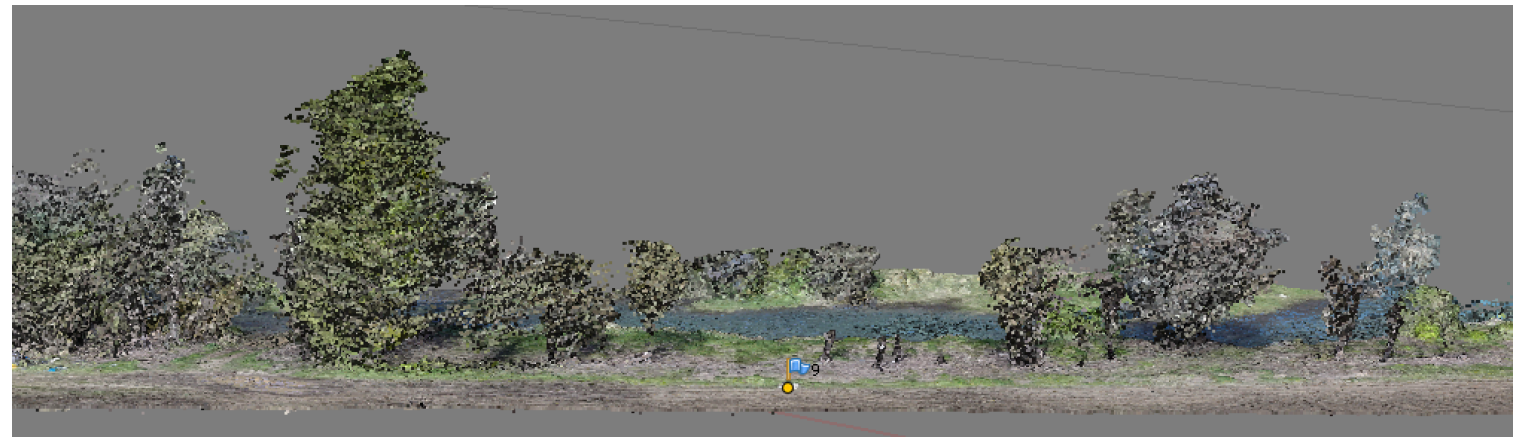

Figure 12: Detail of dense point cloud

Each point in the point cloud contains data on the longitude, latitude, altitude, and color. When the point cloud is first processed, the coordinates are unprojected WGS 1984. The program FUSION (http://forsys.cfr.washington.edu/fusion.html) is used to analyze the point cloud data. FUSION is built to handle UTM coordinates, thus the point cloud must be converted in Photoscan. The coordinates of the point cloud are converted to WGS 1984 / UTM zone10N (EPSG::32610). 


\subsection{Point Cloud Analysis}

The project area was split into four sections for analysis (Fig. 13). Section 3 (displayed in orange) was used for derivation of correlation parameters to the groundtruth data, and the remaining three sections were used for verification of the method. Section 3 was chosen as the calibration section because it had the most diverse terrain, causing the parameters produced from this section to provide the lowest overall error and best correlation with TFT data.

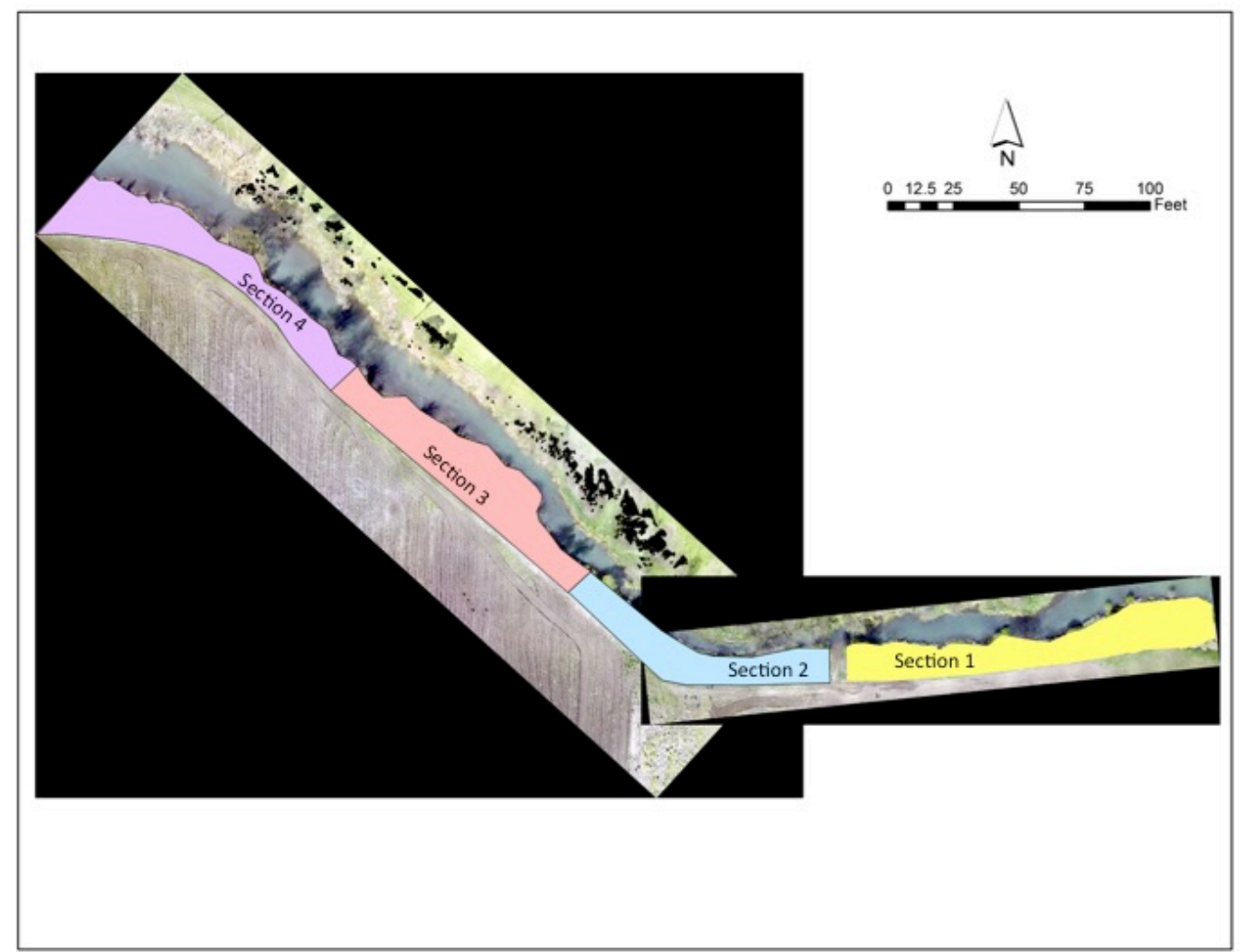

Figure 13: Analysis sections used for calibration and verification

The point cloud is exported from Agisoft Photoscan and imported into FUSION software. FUSION is a data management and visualization software designed for analyzing forest vegetation characteristics using LiDAR data [7]. FUSION can be used to 
view a height map of the point cloud (Fig. 14) and manually navigate throughout the pointcloud to measure individual trees (Fig. 15). Programs in FUSION were used to analyze stem inventory in the site area using two different techniques for stems above 7 feet and stems below 7 feet. The programs in FUSION are run through the Command Prompt on a Windows Operating system. The programs are called out and a combination of the desired inputs and switches are used to obtain the desired outputs.

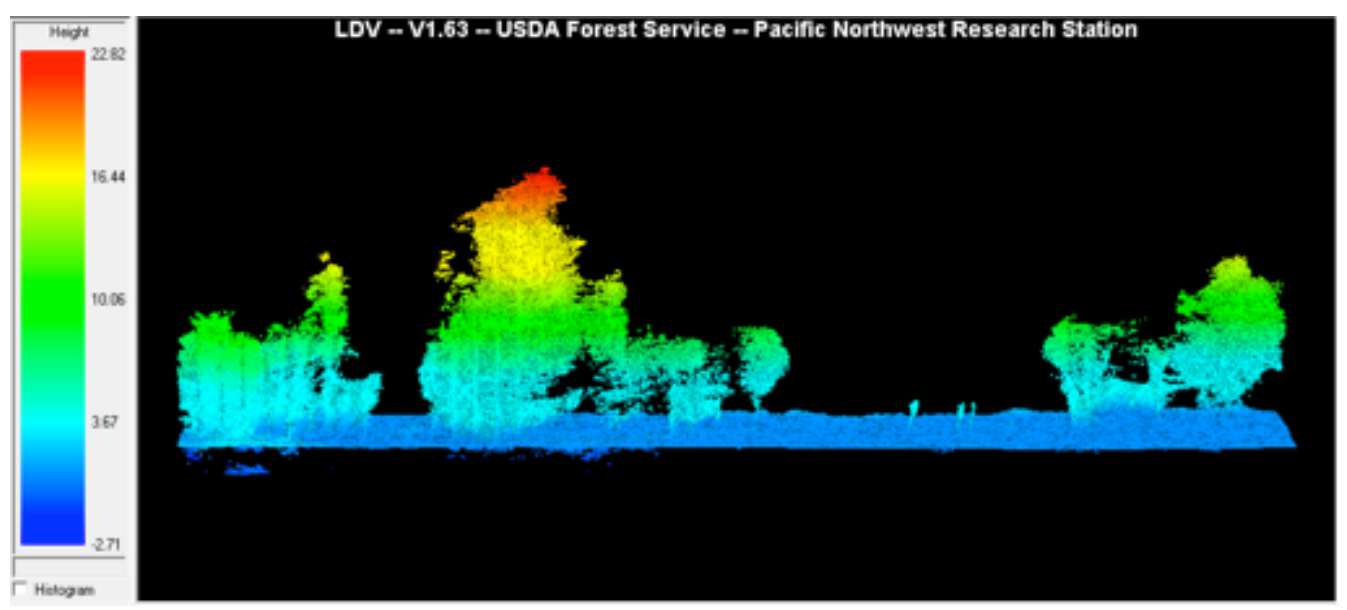

Figure 14: Point cloud visualization in FUSION 


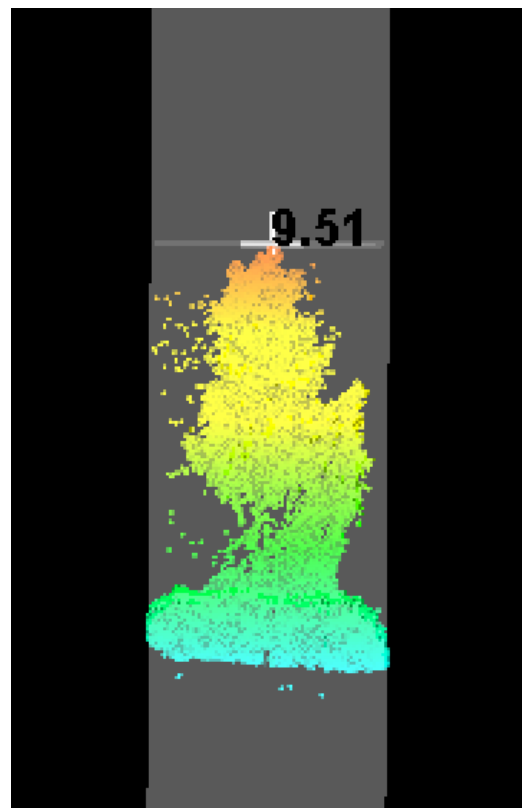

Figure 15: Individual tree measurement in FUSION

\subsubsection{Stem count inventory methods}

Two methods were used for obtaining stem counts above and below 7 feet. Using the same method implemented for tall stems did not yield accurate results when implemented for short stems; this was due to the resolution of the GoPro along with the terrain of the study area. The presence of many taller trees caused many of the smaller trees to be concealed, thus a new method was developed to count stems in the 0-3 feet and 3-7 feet classes.

\subsubsection{Above 7 feet stem inventory method}

For stems above 7 feet an algorithm composed of programs in FUSION was used (Fig. 16). 


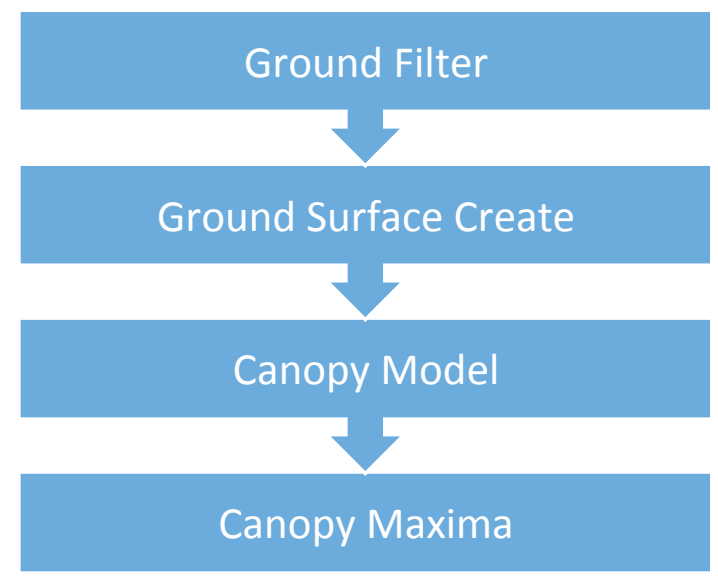

Figure 16: Above 7 feet stem count algorithm

The GroundFilter tool differentiates the ground points from the non ground points by establishing an intermediate surface in the middle of the point cloud and assigning weights to each point based on their distance from the surface and position either above or below the surface. A set number of iterations are run as the surface moves closer to the actual ground. On the last iteration ground points are classified based on their distance from the last surface. The input for this tool is the point cloud exported from Photoscan, the output is a point cloud only containing points that lie on the probable ground surface.

Next, the GridSurfaceCreate tool was used to create a ground surface or Digital Terrain Model (DTM) from the ground point cloud file by averaging the point elevation values in a specified cell size. The input for this tool is the ground point cloud output from the GroundFilter program, the cell size used to average the points, the units of the data in the point cloud, the coordinate system and coordinate system zone for the surface (Table 9). The output is a surface file with .dtm format. A portion of the surface created is shown in Fig. 17. 
Table 9: GridSurfaceCreate tool inputs

\begin{tabular}{|l|l|}
\hline \multicolumn{1}{|c|}{ Parameter } & \multicolumn{1}{c|}{ Input } \\
\hline Cell Size & 2.62 feet \\
\hline Units of point cloud data & M \\
\hline Coordinate system & UTM \\
\hline Coordinate system zone & 10 \\
\hline
\end{tabular}

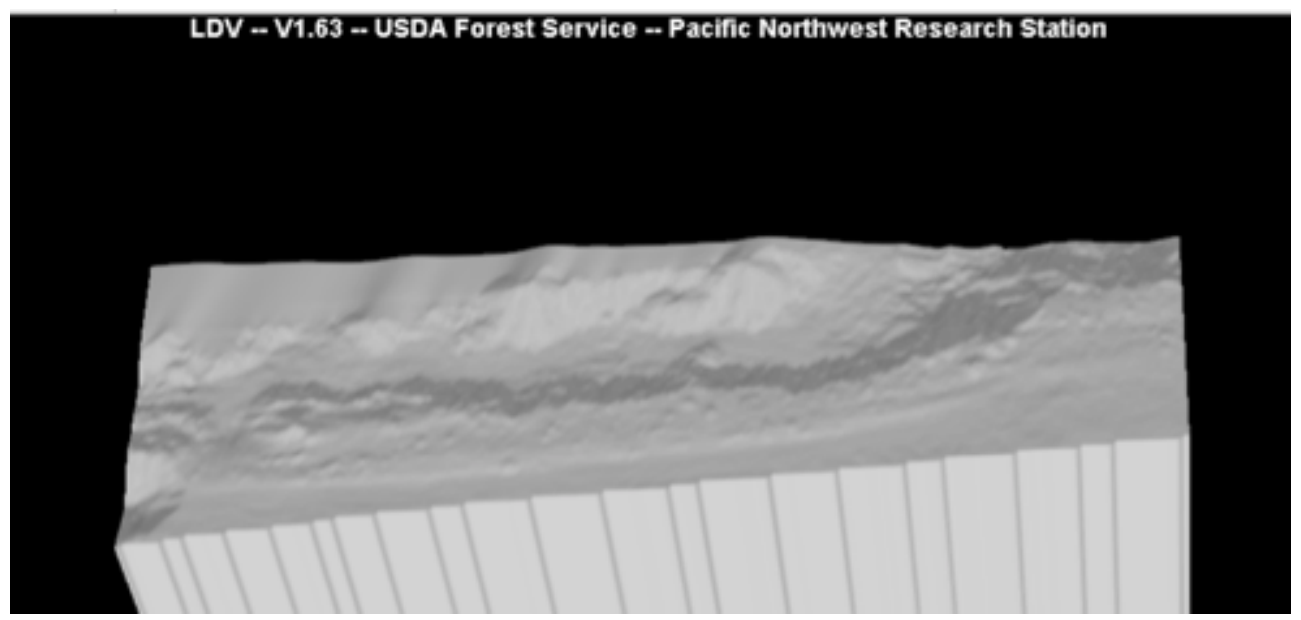

Figure 17: A portion of the ground surface

The CanopyModel tool in FUSION is used next to create a Canopy Height Model (CHM). Using the original point cloud exported from Photoscan and the bare earth model created from the GridSurfaceCreate tool, CanopyModel subtracts the ground elevations from the point cloud elevations to produce the CHM (Fig. 18).

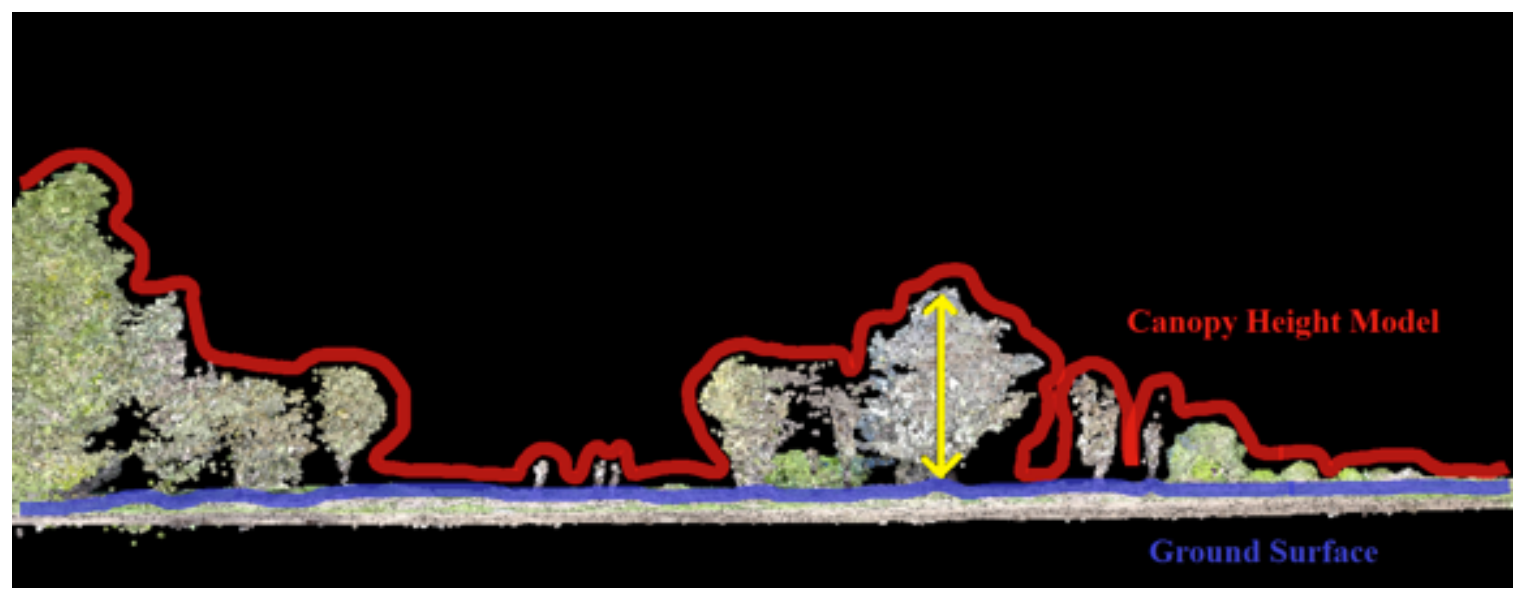

Figure 18: Canopy height model creation 
The inputs for CanopyModel are the ground surface file, the point cloud, cell size, units of the point cloud, and the coordinate system and zone for the canopy model (the same cell size, units, and coordinate system were used form the GridSurfaceCreate tool). The output is a surface file with cell values containing height above ground data. The ground switch is used to specify the bare-earth surface model that normalizes the point cloud. The ascii switch is used to write the output of the surface in ASCII raster format in addition to the DTM format so it is able to be opened in ArcGIS.

Heights and locations for stems above 7 feet can then be determined using the CanopyMaxima tool in FUSION. CanopyMaxima determines the heights and locations of trees by searching for local maxima by finding the highest point within a window that varies its size based on the elevation. A larger tree will have a wider canopy thus the window size used to search for the maxima will be larger. The input for CanopyMaxima is the CHM created with the CanopyModel tool. The output is a CSV file containing the heights and locations of the maxima (trees). The parameter that predicts the accuracy of CanopyMaxima is the cell size used to create the CHM. A cell size that is too large will produce a stem count that is too low and a cell size that is too small will produce a stem count that is too high. The cell size was calibrated with the ground truthed TFT data. The cell size was manipulated until section 3 came within $10 \%$ of TFT data. The final cell size used was 2.62 feet. It was then applied to the remaining areas to determine the results. 


\subsubsection{Below 7 feet inventory}

For counting stems below 7 feet an algorithm composed of programs in FUSION, ArcGIS, and calibration with the TFT data was developed (Fig. 19). The first two steps in the algorithm are identical to the fist two steps in the above 7 feet stem count algorithm and the same ground surface model was used.

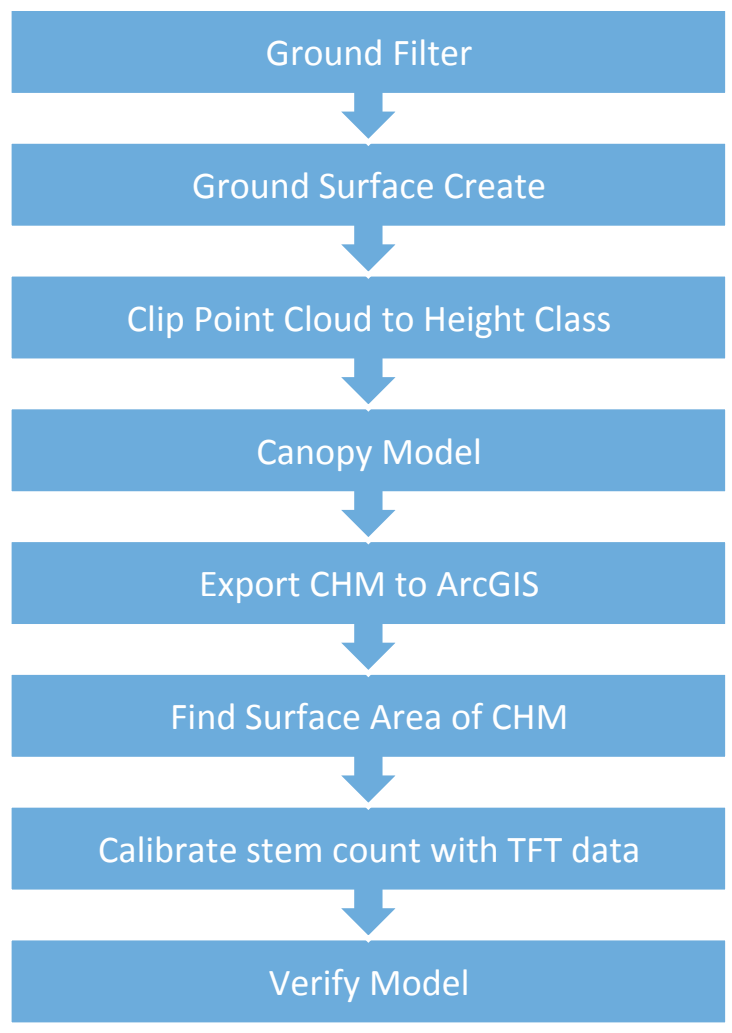

Figure 19: Below 7 feet stem count algorithm

In FUSION, the point cloud was clipped using the ClipData tool to only contain points between 0 and 3 feet and 3 and 7 feet, for each of the two lower height classes specified by TFT. The inputs for the ClipData tool are the point cloud exported from Photoscan and the extent of the point cloud in terms of a minimum $\mathrm{X}$ and $\mathrm{Y}$ and maximum $\mathrm{X}$ and $\mathrm{Y}$ bounding box. The $\mathrm{dtm}$ and height switches are used in combination with the ground surface model to convert the point elevations to heights above ground 
using the ground surface file. The zmin and zmax switches are then used to only include points above and below specified heights in the output. An example of a portion of the clipped point cloud below 3 feet is shown in Fig. 20.

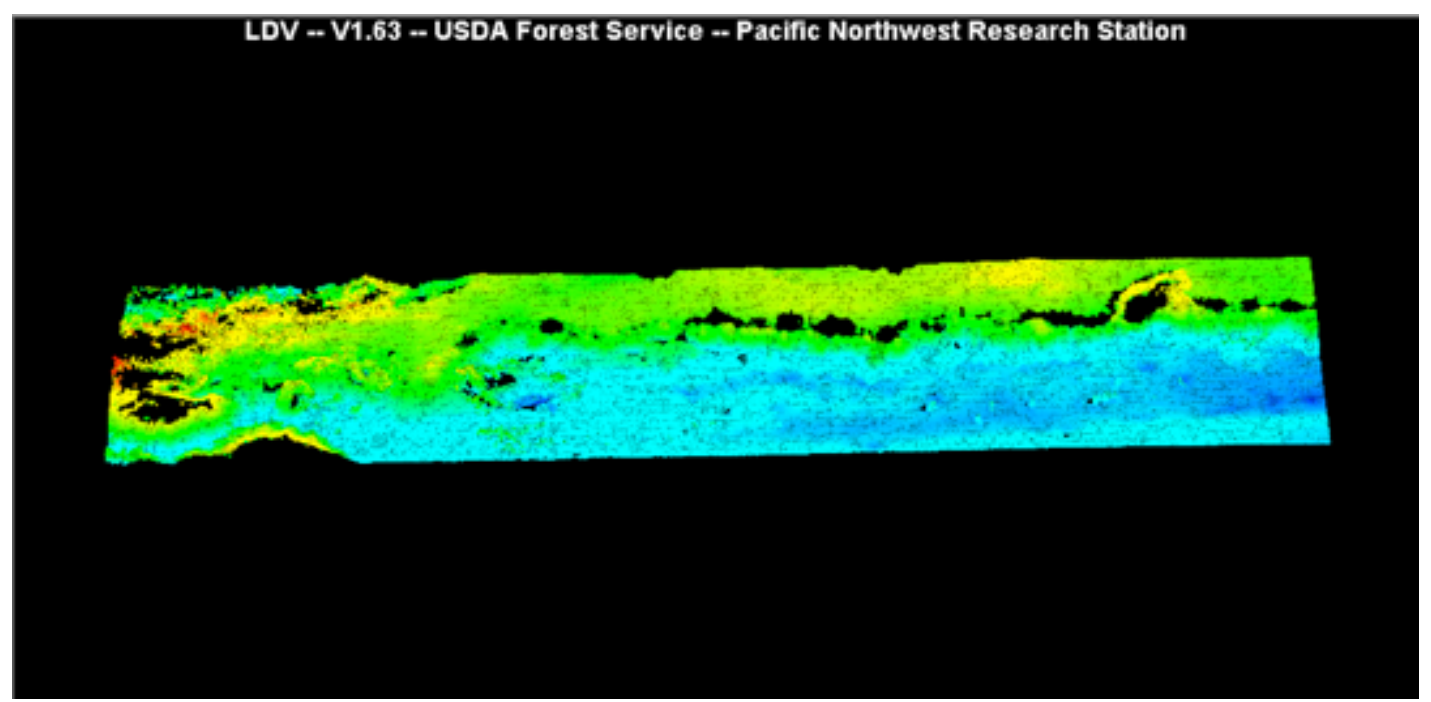

Figure 20: Portion of point cloud clipped below 3 feet

The height map of the clipped point cloud shows the heights relative to each other of each point. The black areas show where taller trees have been cut out of the point cloud at the maximum height for each class.

Once the point cloud is clipped to each height class, a CHM is created using the CanopyModel tool in FUSION. The inputs for the CanopyModel tool are the clipped point cloud, the ground surface model, the cell size, units of the output, coordinate system and zone of the output model. The cell size calibrated from the $>7$ feet analysis of 2.62 feet was used. The CHM is then imported into ArcGIS. The ascii switch is used to write the output surface in ASCII raster format so it could be imported into ArcGIS. Once the CHM is imported into ArcGIS (Fig. 21 and Fig. 22), it is clipped to each section using the 
Clip tool in the Raster processing toolbox. The polygons for each section (Fig. 13) are input into the Clip tool along with the CHM raster for each height class to output the 0 to 3 feet and 3 to 7 feet height class CHM for each section. The Surface Volume tool in ArcGIS is used to output the surface area for each section (SA).

The hypothesis for this method is that the SA of the CHM for each height class will correlate with stem counts because the more variation from a flat surface leads to more surface area, which indicates more stems. The SA for the calibration area is divided by the TFT stem count for the calibration section to obtain a conversion factor, CF (Eqn. 1). This $\mathrm{CF}$ is then applied to the remaining areas to acquire a stem count for the entire project site (Eqn. 2).

$$
\begin{aligned}
& C F=\frac{S A}{\text { TFT Stems } / \text { Section }} \\
& \text { UAV Stems }=\frac{S A}{C F}
\end{aligned}
$$

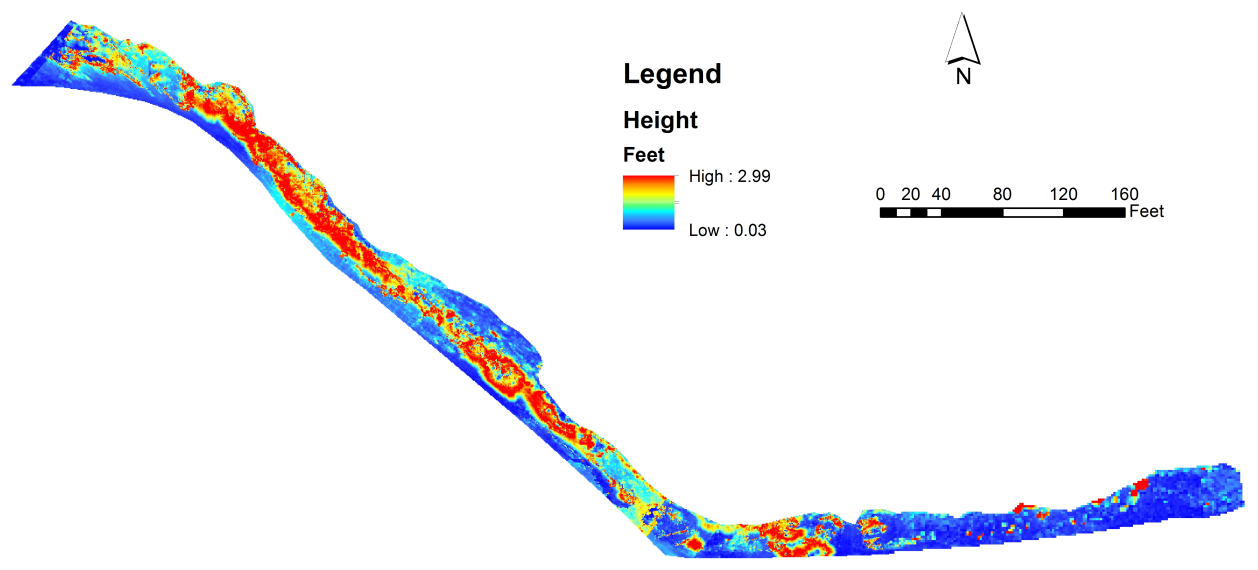

Figure 21: CHM of 0 to 3 feet height class 


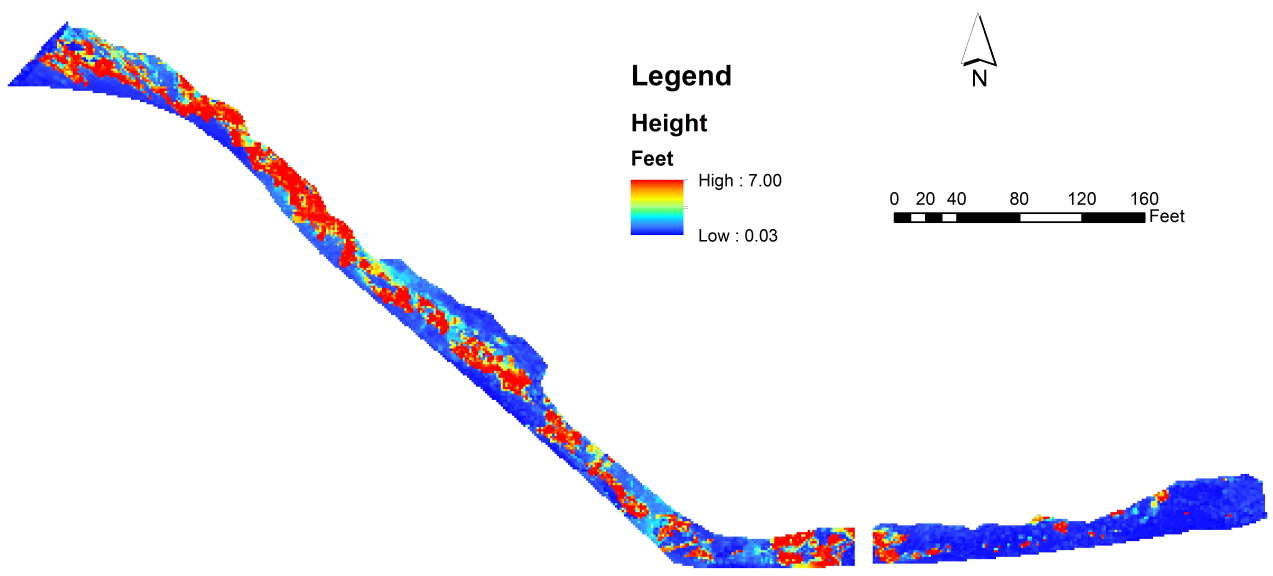

Figure 22: CHM of 3 to 7 feet height class 


\section{Results and Discussion}

TFT's monitoring data proved to be very low resolution, making it difficult to compare to the stem count obtained from the UAV. For this reason, the stem count results obtained by the UAV were compared to TFT monitoring results using two methods of analyzing the ground-truth data provided by TFT. The first method, termed the Proportional Allocation Method, used a single, average stem/acre value for each height class for the entire site. The second method, termed the Transects Averaged Method, averaged the stem counts from the three closest transects to each section in an attempt to obtain a more localized result, giving each section a different stem/acre average. The results from each method were compared to the UAV results for each area and height class.

\subsection{Proportional Allocation Method: Overall Field Data Results Comparison}

In the Proportional Allocation method, the overall stem counts calculated by TFT (Table 10) were applied to each section for comparison against the UAV generated data in the 0-3 feet and 3-7 feet height classes (Table 11). The locations and sizes of the UAVderived stems above 7 feet were geolocated (Fig. 23) and compared to TFT data (Table 12). The mean of the results for the three non-calibration sections was calculated to produce an overall stem/acre result for each height class (Table 13).

\begin{tabular}{|c|c|c|}
\hline Stem height [ft] & Stem/acre & $\begin{array}{c}\mathbf{8 0 \%} \text { Confidence } \\
\text { Interval } \\
\text { [stem/acre] }\end{array}$ \\
\hline $0.5-3.0$ & 1836 & $+/-308$ \\
\hline $3.0-7.0$ & 78 & $+/-50$ \\
\hline$>7.0$ & 70 & $+/-58$ \\
\hline Total & 1984 & $+/-417$ \\
\hline
\end{tabular}




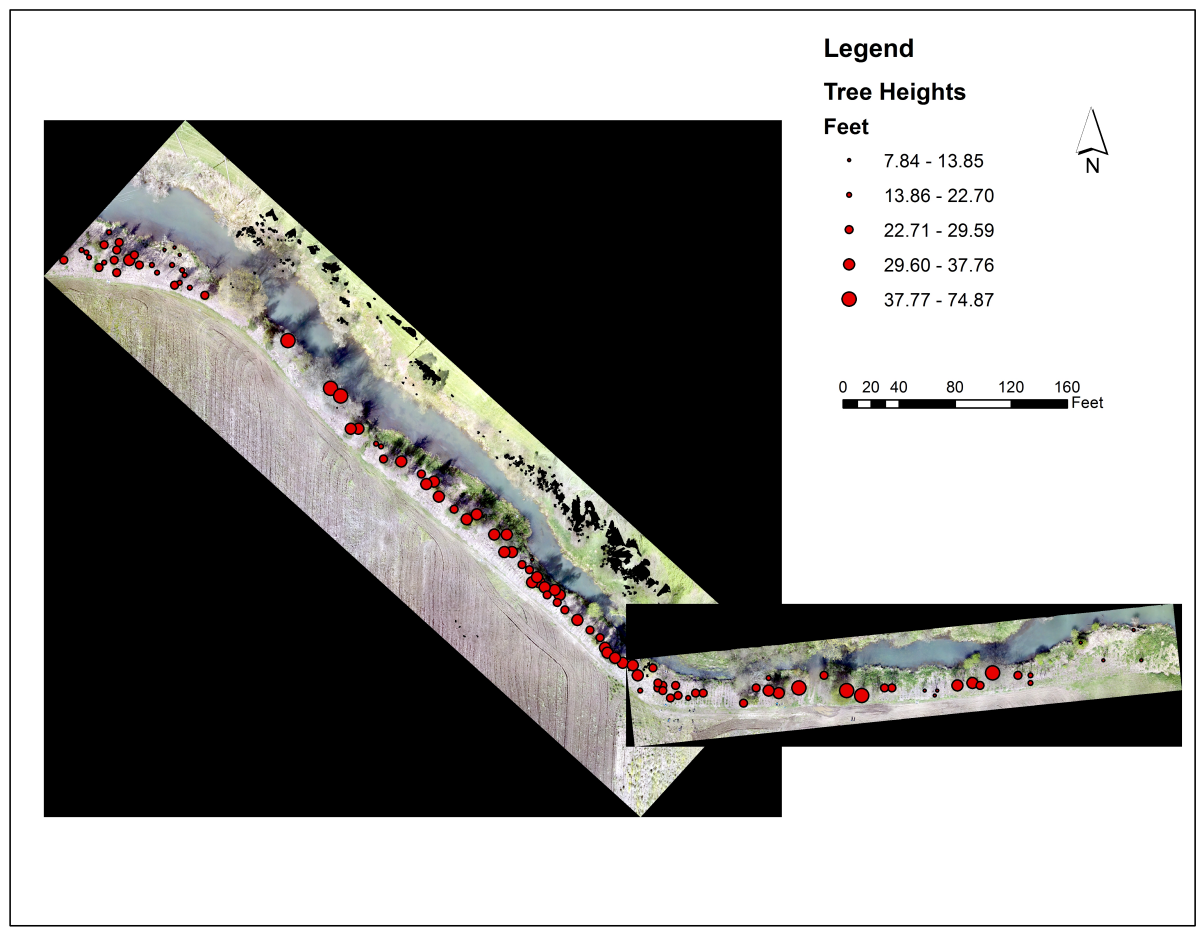

Figure 23: Greater than 7 feet tree locations and heights

Table 11: Proportional Allocation TFT vs. UAV comparison results for 0-3 feet and 3-7 feet

\begin{tabular}{|c|c|c|c|c|c|c|c|c|}
\hline \multicolumn{9}{|c|}{0 to 3 Feet } \\
\hline Section & Acres & $\begin{array}{c}\text { TFT } \\
\text { [stems/ } \\
\text { acre] }\end{array}$ & $\begin{array}{c}\text { TFT } \\
\text { Stems }\end{array}$ & $\begin{array}{c}\text { Surface } \\
\text { Area of } \\
\text { СНМ }\end{array}$ & $\begin{array}{c}\text { CF } \\
\text { Applied } \\
\text { (Eq. 1) }\end{array}$ & $\begin{array}{c}\text { Calculated } \\
\text { Stems }\end{array}$ & $\begin{array}{l}\text { Calculated } \\
\text { Stems/Acre }\end{array}$ & Error \\
\hline 1 & 0.48 & 1836 & 881.3 & $1,851.4$ & 2.1 & 864.6 & $1,801.2$ & $1.9 \%$ \\
\hline 2 & 0.33 & 1836 & 605.9 & $1,339.0$ & 2.1 & 625.3 & $1,894.8$ & $-3.2 \%$ \\
\hline 3 & 0.49 & 1836 & 899.7 & $1,926.5$ & 2.1 & 899.6 & $1,836.0$ & $0.0 \%$ \\
\hline 4 & 0.47 & 1836 & 862.9 & $1,858.6$ & 2.1 & 867.9 & $1,846.7$ & $-0.6 \%$ \\
\hline \multicolumn{9}{|c|}{3 to 7 Feet } \\
\hline Section & Acres & $\begin{array}{c}\text { TFT } \\
\text { [stems/ } \\
\text { acre] }\end{array}$ & $\begin{array}{c}\text { TFT } \\
\text { Stems }\end{array}$ & $\begin{array}{c}\text { Surface } \\
\text { Area of } \\
\text { СНМ }\end{array}$ & $\begin{array}{c}\text { CF } \\
\text { Applied } \\
\text { (Eq. 1) }\end{array}$ & $\begin{array}{c}\text { Calculated } \\
\text { Stems }\end{array}$ & $\begin{array}{l}\text { Calculated } \\
\text { Stems/Acre }\end{array}$ & Error \\
\hline 1 & 0.48 & 78 & 37.4 & 292.2 & 25.6 & 11.4 & 23.8 & $69.5 \%$ \\
\hline 2 & 0.33 & 78 & 25.7 & 744.2 & 25.6 & 29.1 & 88.2 & $-13.0 \%$ \\
\hline 3 & 0.49 & 78 & 38.2 & 977.8 & 25.6 & 38.2 & 78.0 & $0.0 \%$ \\
\hline 4 & 0.47 & 78 & 36.7 & $1,294.1$ & 25.6 & 50.6 & 107.6 & $-38.0 \%$ \\
\hline
\end{tabular}


Table 12: Proportional Allocation TFT vs. UAV comparison results for $>7$ feet stems

\begin{tabular}{|c|r|r|r|r|r|r|}
\hline Area & Acres & $\begin{array}{c}\text { TFT } \\
\text { [stems/acre] }\end{array}$ & $\begin{array}{c}\text { TFT } \\
\text { Stems }\end{array}$ & \multicolumn{1}{c|}{$\begin{array}{c}\text { UAV } \\
\text { Stems }\end{array}$} & $\begin{array}{c}\text { UAV } \\
\text { Stems/acre }\end{array}$ & Error \\
\hline 1.00 & 0.48 & 70 & 33.6 & 19 & 40 & $-43.5 \%$ \\
\hline 2.00 & 0.33 & 70 & 23.1 & 29 & 88 & $25.5 \%$ \\
\hline 3.00 & 0.49 & 70 & 34.3 & 32 & 65 & $-6.7 \%$ \\
\hline 4.00 & 0.47 & 70 & 32.9 & 38 & 81 & $15.5 \%$ \\
\hline
\end{tabular}

Table 13: Proportional Allocation overall TFT vs. UAV results

\begin{tabular}{|c|c|c|}
\hline & TFT & UAV \\
\hline 0 - 3 feet mean & 1836.0 & 1847.6 \\
\hline 3 - 7 feet mean & 78.0 & 73.2 \\
\hline over 7 feet mean & 70.0 & 69.4 \\
\hline & & \\
\hline Sum & 1984.0 & 1990.2 \\
\hline Total Error & $0.3 \%$ & \\
\hline
\end{tabular}

Linear regressions and a Bland-Altman analysis were used to compare the UAV results to the ground-truth. Data and results from section 3 were excluded, as this data was used in the derivation of the method. The linear regression on the first comparison method indicated a slope of 1.002 and an $\mathrm{R}^{2}$ value of 1 (Fig. 24). A Bland-Altman analysis, commonly used to compare agreement between two measurement methods, was used to compare TFT's monitoring data to the UAV collected data. Bland-Altman analysis calculates the mean and standard deviation of the differences between the two measurement methods. The analysis indicated that all the differences between the two methods lie within two standard deviations of the mean difference of -5.6 stems/acre resulting in a 95\% confidence interval that the UAV's measurements will be within 14 stems/plot of the overall TFT results. The Bland-Altman plot is shown in Fig. 25. The ground truth data is reported with an $80 \%$ confidence interval of $+/-844$ stems/plot, thus 
the UAV was able to estimate stems well within the confidence interval of the ground truth data.

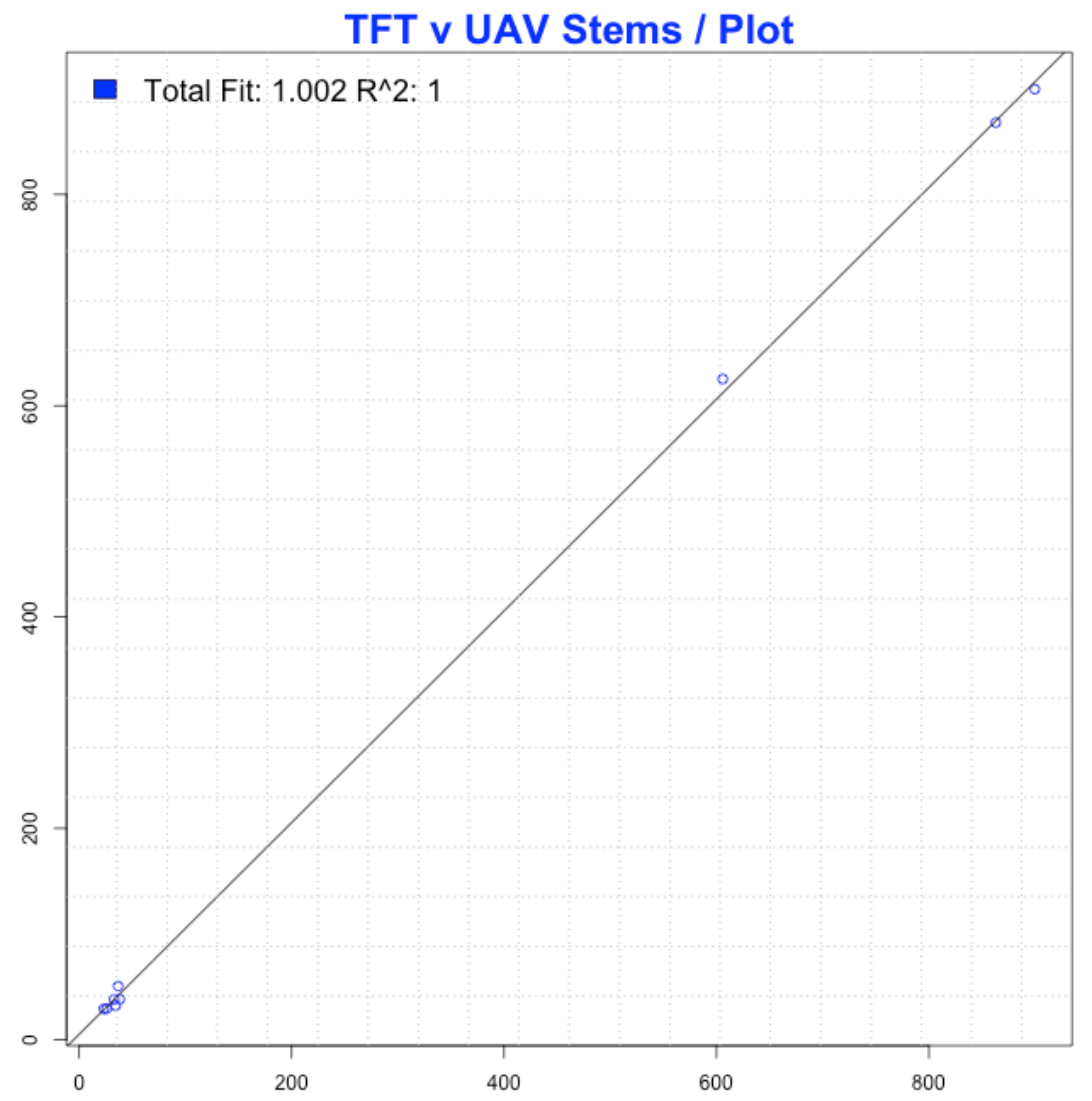

Figure 24: Linear regression of TFT vs. Drone results for the Proportional Allocation Method 


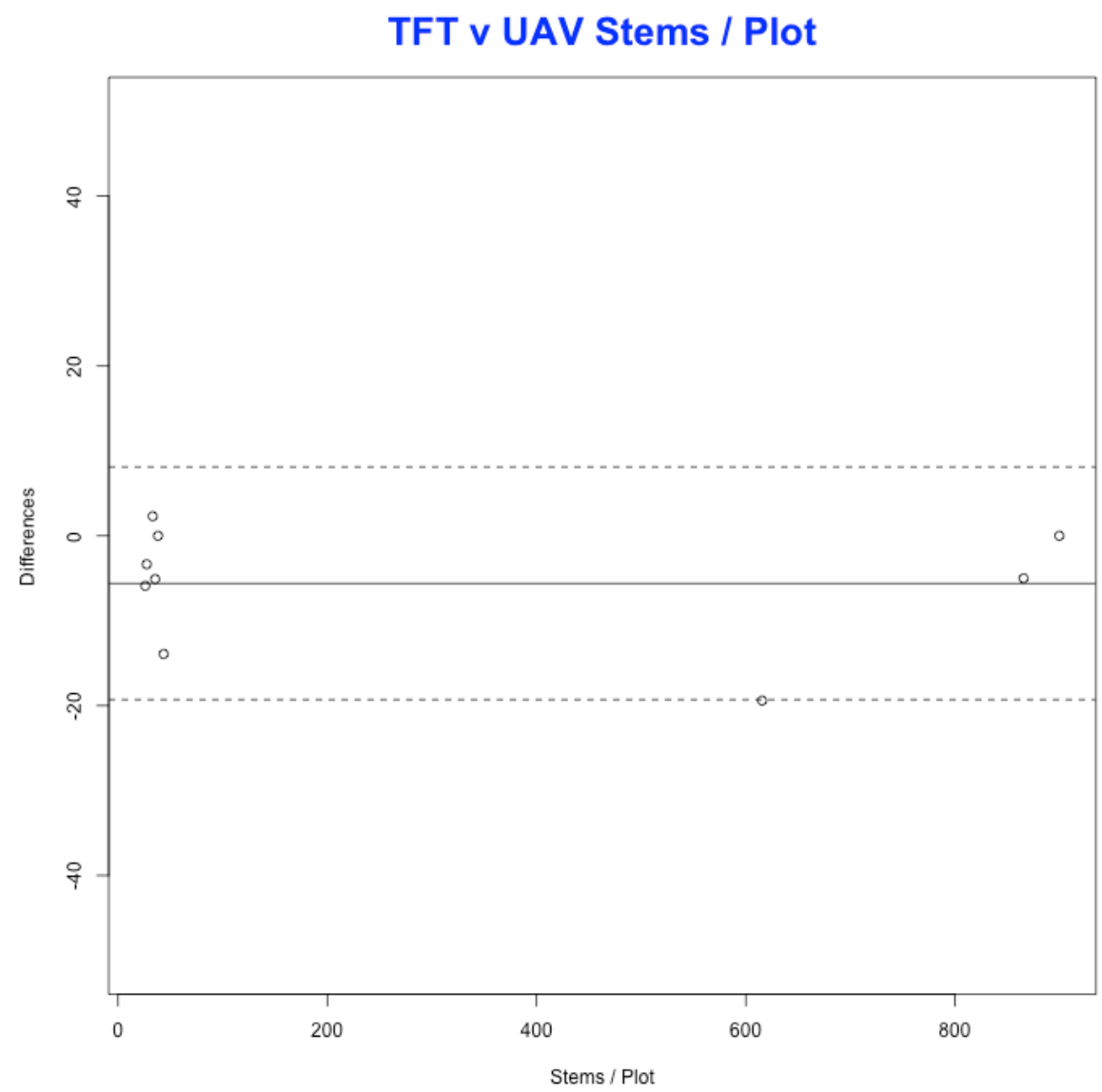

Figure 25: Bland Altman analysis of TFT vs. Drone results for the Proportional Allocation Method

6.2 Transects Averaged Method: Localized Field Data Results Comparison

The Transects Averaged method averaged TFT's raw data in the three closest transects to each section. These averages create a unique stem/acre result for each area. These new results are compared to the UAV data. The calculation of the averages for each area is shown in Table 14. 
Table 14: Three closest transects averaged per area

\begin{tabular}{|r|r|r|r|r|r|r|r|}
\hline Section & Transects & $\begin{array}{c}\text { Average } \\
\mathbf{5 - 3} \mathbf{~ f t}\end{array}$ & $\begin{array}{c}\text { Average } \\
\mathbf{3 - 7} \mathbf{f t}\end{array}$ & $\begin{array}{r}\text { Average } \\
\mathbf{7}\end{array}$ & $\begin{array}{c}\mathbf{0 - 3} \mathbf{f t} \\
\text { stem/acre }\end{array}$ & $\begin{array}{c}\mathbf{3 - 7} \mathbf{~ f t} \\
\text { stem/acre }\end{array}$ & $\begin{array}{c}>\mathbf{7 ~ f t} \\
\text { stem/acre }\end{array}$ \\
\hline 1 & $9,10,11$ & 18.83 & 1.00 & 1.33 & 2050.95 & 108.90 & 145.20 \\
\hline 2 & $10,9,8$ & 18.83 & 1.00 & 1.33 & 2050.95 & 108.90 & 145.20 \\
\hline 3 & $8,6,5$ & 13.83 & 0.67 & 0.17 & 1506.45 & 72.60 & 18.15 \\
\hline 4 & $6,5,1$ & 15.50 & 1.00 & 0.50 & 1687.95 & 108.90 & 54.45 \\
\hline & & & & $\begin{array}{r}\text { Average } \\
\text { Stem/Acre }\end{array}$ & $\mathbf{1 8 2 4 . 0 8}$ & $\mathbf{9 9 . 8 3}$ & $\mathbf{9 0 . 7 5}$ \\
\hline
\end{tabular}

Once the new stem/acre numbers were calculated for each section, they were compared to the UAV generated data, again using section 3 for calibration of the conversion factor (Table 15). The stems count produced by the UAV data for stems above 7 feet was not recalibrated with the localized stem data. There were so few stems above 7 feet that extrapolating the TFT data for only three transects caused inaccurate results. The UAV data was still compared to localized TFT data, but the calibrated results from the Proportional Allocation method remained the same.

Table 15: Transects Averaged TFT vs. UAV comparison results for 0-3 feet and 3-7 feet

\begin{tabular}{|r|r|r|r|r|r|r|r|r|}
\hline \multicolumn{2}{|c|}{ 0 to 3 Feet } & TFT & TFT & Surface \\
Section & Acres & $\begin{array}{c}\text { Trea of } \\
\text { CHM }\end{array}$ & $\begin{array}{c}\text { CF } \\
\text { Applied }\end{array}$ & $\begin{array}{c}\text { Calculated } \\
\text { Stems }\end{array}$ & $\begin{array}{c}\text { Calculated } \\
\text { Stems/Acre }\end{array}$ & Error \\
\hline 1 & 0.48 & $2,050.95$ & 984.46 & $1,851.44$ & 2.61 & 709.40 & $1,477.91$ & $27.94 \%$ \\
\hline 2 & 0.33 & $2,050.95$ & 676.81 & $1,339.01$ & 2.61 & 513.06 & $1,554.72$ & $24.20 \%$ \\
\hline 3 & 0.49 & $1,506.45$ & 738.16 & $1,926.50$ & 2.61 & 738.16 & $1,506.45$ & $0.00 \%$ \\
\hline 4 & 0.47 & $1,687.95$ & 793.34 & $1,858.60$ & 2.61 & 712.14 & $1,515.20$ & $10.23 \%$ \\
\hline 3 to 7 Feet & & TFT & TFT & Surface & CF & Calculated & Calculated & Error \\
Section & Acres & Stems & Stems/Acre & \\
\hline 1 & 0.48 & 108.90 & 52.27 & 292.21 & 27.48 & 10.63 & 22.15 & $79.66 \%$ \\
\hline 2 & 0.33 & 108.90 & 35.94 & 744.23 & 27.48 & 27.08 & 82.05 & $24.65 \%$ \\
\hline 3 & 0.49 & 72.60 & 35.57 & 977.75 & 27.48 & 35.57 & 72.60 & $0.00 \%$ \\
\hline 4 & 0.47 & 72.60 & 34.12 & $1,294.07$ & 27.48 & 47.08 & 100.18 & $-37.98 \%$ \\
\hline
\end{tabular}


Table 16: Transects Averaged TFT vs. UAV comparison results for $>7$ feet

\begin{tabular}{|c|c|c|c|c|c|c|}
\hline Area & Acres & $\begin{array}{c}\text { TFT } \\
\text { [stems/acre] }\end{array}$ & $\begin{array}{c}\text { TFT } \\
\text { Stems }\end{array}$ & $\begin{array}{c}\text { UAV } \\
\text { Stems }\end{array}$ & $\begin{array}{c}\text { UAV } \\
\text { Stems/acre }\end{array}$ & Error \\
\hline 1.00 & 0.48 & 145.20 & 69.696 & 19 & 40 & $-72.74 \%$ \\
\hline 2.00 & 0.33 & 145.20 & 47.916 & 29 & 88 & $-39.48 \%$ \\
\hline 3.00 & 0.49 & 18.15 & 8.8935 & 32 & 65 & $259.81 \%$ \\
\hline 4.00 & 0.47 & 18.15 & 8.5305 & 38 & 81 & $345.46 \%$ \\
\hline
\end{tabular}

Table 17: Transects Averaged TFT vs. UAV overall results

\begin{tabular}{|c|c|c|c|}
\hline & TFT & Drone & Error \\
\hline 0 - 3 feet mean & 1929.95 & 1515.94 & $21.45 \%$ \\
\hline 3 - 7 feet mean & 96.80 & 68.13 & $29.62 \%$ \\
\hline Over 7 feet mean & 81.68 & 69.00 & $15.52 \%$ \\
\hline Sum & & & \\
\hline & 2108.43 & 1653.07 & \\
\hline Total Error & $21.60 \%$ & & \\
\hline
\end{tabular}

A linear regression and Bland Altman analysis were also performed on the

Transects Averaged method results. The linear regression shows an $\mathrm{R}^{2}$ value of 0.98 and a total fit of 0.88 (Fig. 26). The Bland-Altman (Fig. 27) analysis shows that all the differences between the two methods lie within two and a half standard deviations of the mean difference of 23 stems/acre resulting in a $99 \%$ confidence interval that the UAV's measurements will be within 159 stems/plot of the overall TFT results. This result also lies well within TFT's $80 \%$ confidence interval of 844 stems/plot. 
TFT v UAV Stems / Plot

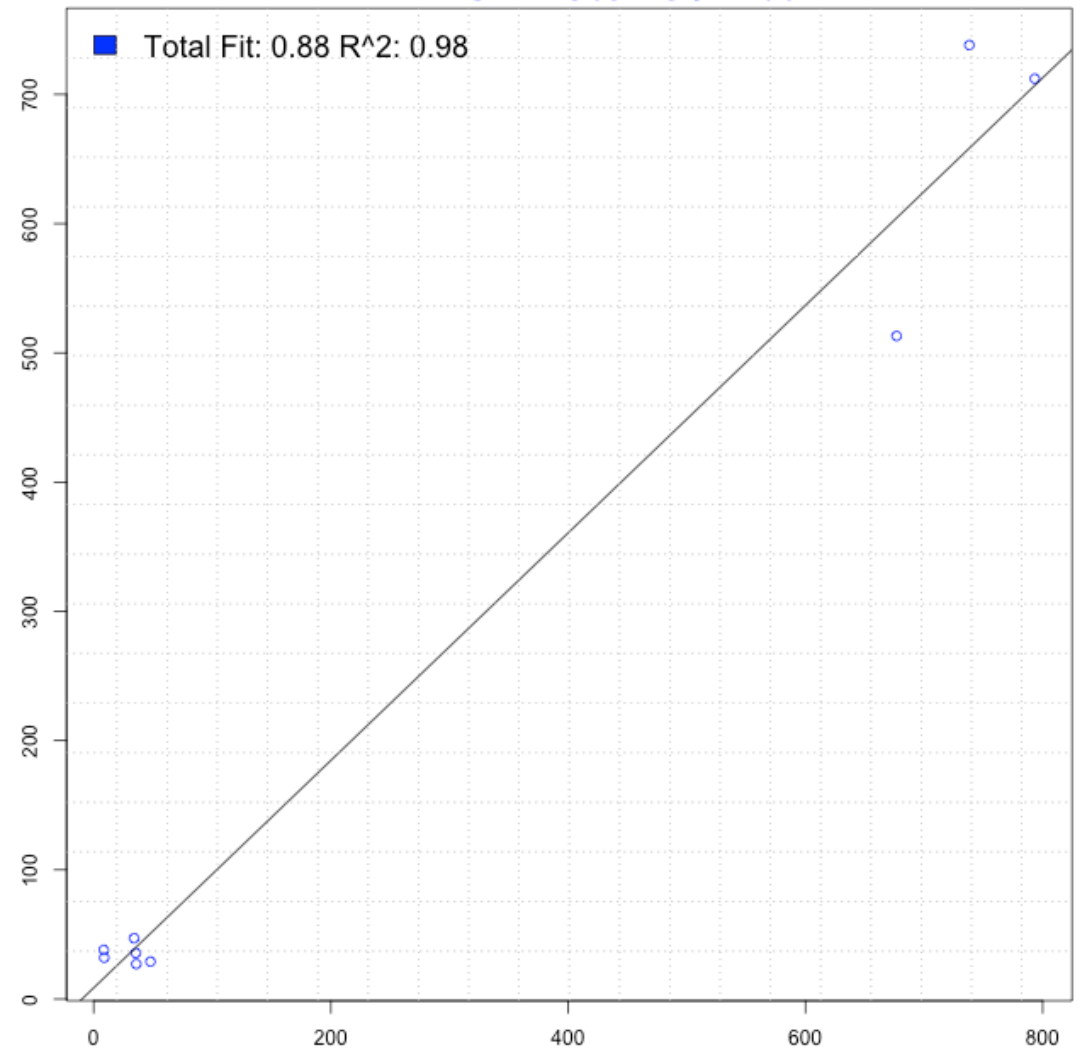

Figure 26: Linear regression of TFT vs. Drone results for Method 2 


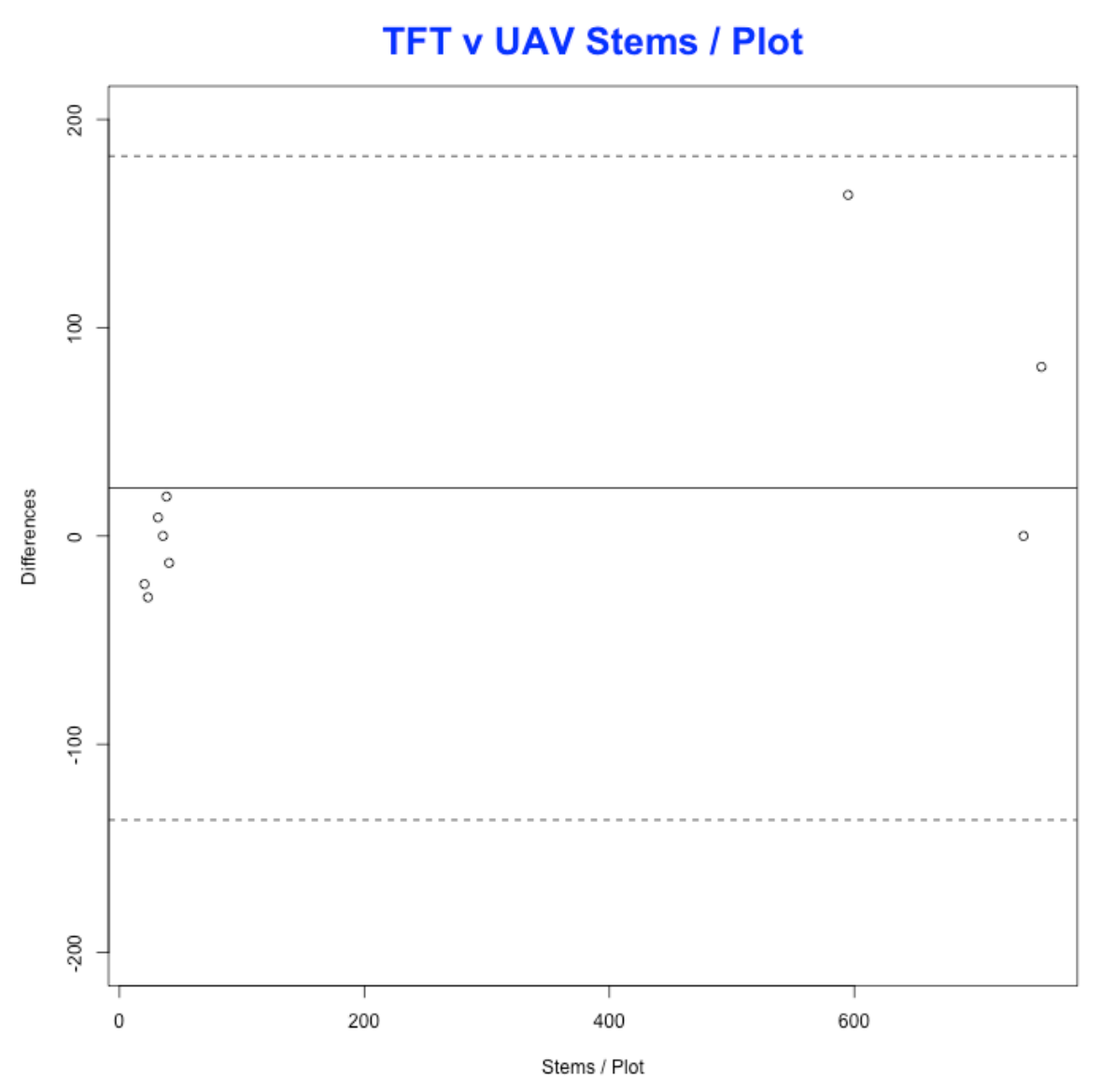

Figure 27: Bland Altman analysis of TFT vs. Drone results for Method 2

The errors produced by using different sections for calibration were analyzed to evaluate the impact of the selection of the calibration section. The results showed that the model is sensitive to change in calibration section (Table 18 and Table 19) but the overall errors observed do not show an unviable model for any of the calibration sections. 
Table 18: Proportional Allocation error analysis

\begin{tabular}{|c|c|c|}
\hline \multicolumn{3}{|l|}{ Overall } \\
\hline $\begin{array}{l}\text { Calibration } \\
\text { Section }\end{array}$ & $\begin{array}{c}\text { Overall Error } \\
{[\%]}\end{array}$ & $\mathbf{R}^{2}$ \\
\hline 1 & 10.51 & 0.99 \\
\hline 2 & 3.00 & 1.00 \\
\hline 3 & 0.31 & 1.00 \\
\hline 4 & 1.24 & 1.00 \\
\hline \multicolumn{3}{|l|}{0 to 3 feet } \\
\hline $\begin{array}{l}\text { Calibration } \\
\text { Section }\end{array}$ & $\begin{array}{c}\text { Conversion } \\
\text { Factor }\end{array}$ & $\begin{array}{c}\text { Overall } \\
\text { Error } \\
{[\%]} \\
\end{array}$ \\
\hline 1 & 2.10 & 2.57 \\
\hline 2 & 2.21 & 2.49 \\
\hline 3 & 2.14 & 0.63 \\
\hline 4 & 2.15 & 0.05 \\
\hline \multicolumn{3}{|l|}{3 to 7 feet } \\
\hline $\begin{array}{l}\text { Calibration } \\
\text { Section }\end{array}$ & $\begin{array}{c}\text { Conversion } \\
\text { Factor }\end{array}$ & $\begin{array}{c}\text { Overall } \\
\text { Error } \\
{[\%]}\end{array}$ \\
\hline 1 & 7.80 & 207.58 \\
\hline 2 & 28.91 & 16.97 \\
\hline 3 & 25.58 & 6.16 \\
\hline 4 & 35.30 & 31.99 \\
\hline
\end{tabular}


Table 19: Transects Averaged error analysis

\begin{tabular}{|c|c|c|}
\hline Overall & & \\
\hline $\begin{array}{c}\text { Calibration } \\
\text { Section }\end{array}$ & Error [\%] & $\mathbf{R}^{2}$ \\
\hline 1 & 35.97 & 0.96 \\
\hline 2 & 11.44 & 0.98 \\
\hline 3 & 21.60 & 0.98 \\
\hline 4 & 12.24 & 0.98 \\
\hline \multicolumn{3}{|l|}{0 to 3 feet } \\
\hline $\begin{array}{c}\text { Calibration } \\
\text { Section }\end{array}$ & $\begin{array}{c}\text { Conversion } \\
\text { Factor }\end{array}$ & $\begin{array}{c}\text { Overall } \\
\text { Error } \\
{[\%]}\end{array}$ \\
\hline 1 & 1.88 & 21.07 \\
\hline 2 & 1.98 & 13.16 \\
\hline 3 & 2.61 & 21.45 \\
\hline 4 & 2.34 & 9.84 \\
\hline \multicolumn{3}{|l|}{3 to 7 feet } \\
\hline $\begin{array}{c}\text { Calibration } \\
\text { Section }\end{array}$ & $\begin{array}{c}\text { Conversion } \\
\text { Factor }\end{array}$ & $\begin{array}{c}\text { Overall } \\
\text { Error } \\
{[\%]}\end{array}$ \\
\hline 1 & 5.59 & 393.07 \\
\hline 2 & 20.71 & 1.81 \\
\hline 3 & 27.48 & 29.62 \\
\hline 4 & 37.92 & 55.88 \\
\hline
\end{tabular}

For the Proportional Allocation method, the overall errors for using each section for calibration of the conversion factor range from $0.31 \%$ to $10.51 \%$. The Transects Averaged method shows to be more sensitive to change in calibration section with overall errors ranging from $11.44 \%$ to $35.97 \%$. All errors lie within TFT's monitoring confidence interval of $+/-844$ stems/site showing that even though the results have variance, they are still within acceptable limits. 


\section{Conclusion}

A comprehensive method was developed to monitor the effectiveness of a riparian restoration project designed by The Freshwater Trust in Springfield, OR, using a UAV. The UAV was used to collect digital images with a GoPro camera. SfM algorithms in Agisoft Photoscan were used to create a three dimensional point cloud from the photos collected. The point cloud was analyzed using multiple software packages to output a stem count similar to that of traditional ground truth methods. There are limitations with the developed method, but the overall output provides an efficient, cost effective technique for riparian restoration monitoring.

The ground truth data collected had a low resolution that was not ideal for comparison against the UAV generated data. TFT's ground truth data was collected for monitoring purposes, not research purposes. Thus, two analysis methods were applied in analyzing the ground truth data in order to compare it to the UAV derived riparian vegetation stem counts. The Proportional Allocation method used the data originally reported by TFT for one stem/acre result averaged for the entire site area for each height class. This result was compared to UAV derived stem counts in four sections on the project site. The Transects Averaged method represented a more localized approach in that it used data from the three closest transects to each section to produce a groundbased riparian vegetation stem count for comparison to UAV stem counts. The two analysis methods were chosen as the available ground truth data was limited and therefore would impact the quality of the comparison. Since TFT data were reported at a stem/acre result for the entire area, any error occurring in field collection is 
systematically applied in all four UAV analysis sections. Using the Proportional Allocation method to analyze the ground truth data showed errors that were $21.3 \%$ less than the Transects Averaged method. This was due to the small sample size used to localize the data. If more ground truth data were collected, a more accurate depiction of the terrain would likely be shown.

The variance in error resulting from implementing different sections for calibration is a portion of the study that requires more investigation moving forward. It is hypothesized that the terrain type correlates with the error. Using section 1 as the calibration section resulted in the highest error; section 1 also had the least amount of stems overall. Terrain with fewer stems means there is less data to calibrate with leading to $10.2 \%$ higher overall error for the Proportional Allocation Method and $14.3 \%$ higher overall error for the Transects Averaged method. Extrapolating fewer stems in the ground-truth data also leads to a higher error.

The approach used to count and locate stems above 7 feet is repeatable and has been verified by multiple studies $[7,25]$. The cell size calibrated with the TFT ground data to achieve the results should be verified by collecting additional data on the same study site along with additional sites. In additional studies ground truth data that includes geolocation of stems should be collected to verify the accuracy of this approach.

It was hypothesized that the surface area of the CHM for each of the lower height classes would correlate with the amount of stems present. The results show that this hypothesis proves to be valid for the accuracy required by environmental monitoring standards. The method developed for counting stems below 7 feet should be explored 
further, both on additional plots and longitudinally on the same plot, ideally with higher resolution ground truth data. Both methods, above and below 7 feet, will likely need sitewise calibration if conducted again.

Another limitation of the study was the processing time it took to create the 3D point cloud. The processing power available required a total processing time of approximately one full week. If more processing power was available, a more efficient method could be conducted. Outsourcing this process could be a promising solution to this problem for future studies.

Through this study and in past studies it is apparent that current riparian restoration monitoring procedures need improvement [2]. The sample size of data collected by surveyors at TFT shows that the final result may not be accurately representing the progression of the restoration project. This study demonstrates that a UAV can generate a digital representation of the project site to provide comprehensive data capable of improving the quality of data collected for riparian restoration monitoring.

Given the ground truth data that was available, the UAV proved to be a feasible, cost-effective instrument to produce information on stem counts for the three height classes of the riparian restoration project managed by TFT. The UAV produced a comprehensive 3D point cloud of the area able to produce forest measurements and mapping products comparable to LiDAR and ground truth methods. Given the limited nature of the ground truth data, it is also conceivable that the UAV approach to riparian vegetation stem counts provides a more accurate and spatially representative result. 


\section{References Cited}

1. Biber, E., The Problem of Environmental Monitoring. University of Colorado Law Review, 2011. 83(1): p. 1-83.

2. Dufour, S., I. Bernez, J. Betbeder, S. Corgne, L. Hubert-Moy, J. Nabucet, S. Rapinel, J. Sawtschuk, and C. Trollè, Monitoring restored riparian vegetation: how can recent developments in remote sensing sciences help? Knowledge and Management of Aquatic Ecosystems 2013. 410(10): p. 1-15.

3. Turner, D., A. Lucieer, and C. Watson, An Automated Technique for Generating Georectified Mosaics from Ultra-High Resolution Unmanned Aerial Vehicle (UAV) Imagery, Based on Structure from Motion (SfM) Point Clouds. Remote Sensing, 2012. 4(5): p. 1392-1410.

4. Lim, K., P. Treitz, M. Wulder, B. St-Onge, and M. Flood, LiDAR remote sensing of forest structure. Progress in Physical Geography, 2003. 27(1): p. 88-106.

5. Lu, D., Q. Chen, G. Wang, E. Moran, M. Batistella, M. Zhang, G.V. Laurin, and D. Saah, Aboveground Forest Biomass Estimation with Landsat and LiDAR Data and Uncertainty Analysis of the Estimates. International Journal of Forestry Research, 2012. 2012(2012).

6. Akay, A. and J. Sessions, Estimating structural properties of riparian forests with airborne LiDAR data. International Journal of Remote Sensing, 2012. 33(22).

7. Edson, C. and M. Wing, Airborne Light Detection and Ranging (LiDAR) for Individual Tree Stem Location, Height, and Biomass Measurements. Remote Sensing, 2011. 3: p. 2494-2528.

8. Remondino, F., L. Barazzetti, F. Nex, M. Scaioni, and D. Sarazzi. UAV Photogrammetry for Mapping and 3D Modeling - Current Status and Future Perspectives. in ISPRS 2011. Zurich: International Archives of the Photogrammetry, Remote Sensing and Spatial Information Sciences.

9. Hummel, S., A.T. Hudak, E.H. Uebler, M.J. Falkowski, and K.A. Megown, $A$ Comparison of Accuracy and Cost of LiDAR versus Stand Exam Data for Landscape Management on the Malheur National Forest. Journal of Forestry, 2011. 109.5: p. 267-273.

10. Horcher, A. and R.J.M. Visser. Unmanned Aerial Vehicles: Applications for Natural Resource Management and Monitoring. in Machines and People, The Interface. 2004. Hot Springs, Arkansas.

11. Laliberte, A., J.E. Herrick, A. Rango, and C. Winters, Acquisition, $\mathrm{Or}$ thorectification, and Object-based Classification of Unmanned Aerial Vehicle $(U A V)$ Imagery for Rangeland Monitoring. Photogrammetric Engineering \& Remote Sensing, 2010. 76(6): p. 661-672.

12. Koh, L.P. and S.A. Wich, Dawn of drone ecology: low-cost autonomous aerial vehicles for conservation. Tropical Conservation Science, 2012. 5(2): p. 121-132.

13. Fritz, A., T. Kattenborn, and B. Koch, UAV-Based Photogrammetric Point Clouds - Tree Stem Mapping in Open Stands in Comparison to Terrestrial Laser Scanner Point Clouds. International Archives of the Photogrammetry, Remote Sensing and Spatial Information Sciences, 2013. XL-1/W2: p. 141-146. 
14. Zarco-Tejada, P.J., R. Diaz-Varela, V. Angileri, and P. Loudjani, Tree height quantification using very high resolution imagery acquired from an unmanned aerial vehicle (UAV) and automatic $3 D$ photo-reconstruction methods. European Journal of Agronomy 2014. 55: p. 89-99.

15. Dandois, J.P. and E.C. Ellis, High spatial resolution three-dimensional mapping of vegetation spectral dynamics using computer vision. Remote Sensing of Environment, 2013. 136: p. 259-276.

16. Salamí, E., C. Barrado, and E. Pastor, UAV Flight Experiments Applied to the Remote Sensing of Vegetated Areas. Remote Sensing, 2014. 6: p. 11051-11081.

17. Dunford, R., K. Michel, M. Gagnage, H. Piégay, and M.L. Trémelo, Potential and constraints of Unmanned Aerial Vehicle technology for the characterization of Mediterranean riparian forest. International Journal of Remote Sensing, 2009. 30(19): p. 4915-4935.

18. Westoby, M.J., J. Brasington, N.F. Glasser, M.J. Hambrey, and J.M. Reynolds, 'Structure-from-Motion' photogrammetry: A low-cost, effective tool for geoscience applications. Geomorphology, 2012. 179(2012): p. 300-314.

19. Mancini, F., M. Dubbini, M. Gattelli, F. Stecchi, F. Stefano, and G. Gabbianelli, Using Unmanned Aerial Vehicles (UAV) for High-Resolution Reconstruction of Topography: The Structure from Motion Approach on Coastal Environments. Remote Sensing, 2013. 5(12): p. 6880-6898.

20. Leslie, M., Stewardship and Monitoring Plan for Riparian Restoration Project Cedar Creek 2.5. 2015, The Freshwater Trust: Portland, OR.

21. Meyer, C., Cedar Creek RM 2.5 Project Design Document, in Ecosystem Credit Accounting System. 2013, Willamette Partnership.

22. Revegetation Monitoring Protocol for Water Quality Trading Projects. 2015, The Freshwater Trust Portland, OR.

23. 3DR Solo User Manual 3D Robotics: Berkeley, CA.

24. Lowe, D., Distinctive image features from scale-invariant keypoints. International Journal of Computer Vison 2004. 60: p. 90-110.

25. Ritter, B.A., Use of Unmanned Aerial Vehicles (UAV) for Urban Tree Inventories, in Forest Resources. 2014, Clemson University: South Carolina. p. 70. 